\title{
Decadal variation of East Asian radiative forcing due to anthropogenic aerosols during 1850-2100, and the role of atmospheric moisture
}

\author{
Jiandong Li1 ${ }^{1,2}$, Wei-Chyung Wang ${ }^{2, *}$, Zhian Sun $^{3}$, Guoxiong Wu1 ${ }^{1}$ Hong Liao ${ }^{4}$, \\ Yimin Liu $^{1}$ \\ ${ }^{1}$ LASG, Institute of Atmospheric Physics, Chinese Academy of Sciences, Beijing 100029, PR China \\ ${ }^{2}$ Atmospheric Sciences Research Center, State University of New York, Albany, New York 12203, USA \\ ${ }^{3}$ Centre for Australian Weather and Climate Research, Australian Bureau of Meteorology, Melbourne, Victoria 3001, Australia \\ ${ }^{4}$ LAPC, Institute of Atmospheric Physics, Chinese Academy of Sciences, Beijing 100029, PR China
}

\begin{abstract}
An aerosol mass dataset simulated from a chemical transport model for the period 1850 to 2100 is used in an atmospheric general circulation model to investigate anthropogenic aerosol radiative forcing (RF) with a focus on East Asia. Compared to the pre-industrial era, the calculated strongest global mean direct RF (DRF) of $-0.30 \mathrm{~W} \mathrm{~m}^{-2}$ at the all-sky top of the atmosphere (TOA) occurs in the 1980s and an indirect cloud albedo forcing (CAF) of $-0.67 \mathrm{~W} \mathrm{~m}^{-2}$ in the 2000s; a maximum atmospheric DRF of $0.48 \mathrm{~W} \mathrm{~m}^{-2}$, mainly by black carbon absorption, is found in the 2010s. Much larger aerosol DRF and CAF values are distributed over East Asia until the 2010s, and the negative surface and positive atmospheric DRF in Eastern China is even projected to maintain a magnitude of $5.0 \mathrm{~W} \mathrm{~m}^{-2}$ until the 2030s. Increasing East Asian aerosol loading has shifted the anthropogenic aerosol RF centers to lower latitudes in the Northern Hemisphere since the 1980s, and this trend is more severe under future mid- and high-range emission scenarios. Further results indicate that larger DRF values over East Asia can be partly attributed to climatological summer atmospheric moisture that is higher relative to Norther American and European regions, which enhances the aerosol hygroscopic effect, then strengthens aerosol optical depth and DRF at clear-sky TOA and surface, and even influences their long-term changes. The observational comparisons reveal that present day simulated surface concentrations of key anthropogenic aerosol species and resulting optical depth are highly underestimated in Eastern China. Further research on simulated meteorology and aerosol features is therefore recommended to reduce the uncertainties in estimating aerosol RF over East Asia.
\end{abstract}

KEY WORDS: Aerosol · Radiative forcing $\cdot$ Cloud albedo forcing $\cdot$ East Asia $\cdot$ Atmospheric moisture Resale or republication not permitted without written consent of the publisher

\section{INTRODUCTION}

Aerosols directly reflect and absorb solar radiation, and indirectly change cloud optical properties and lifetime (Twomey 1977, Albrecht 1989), both yielding significant radiative forcing (RF) on the climate system. Data on the climate effects from natural and anthropogenic aerosols are essential for climate change studies (Ramaswamy et al. 2001, Carslaw et al. 2010).
Particularly, some atmospheric aerosol species and loadings have changed considerably due to changes in their anthropogenic emissions since the pre-industrial era (PI, here taken to be up to 1850). When compared with the PI, Schulz et al. (2006) indicated that the global mean aerosol direct RF (DRF) could be from -0.41 to $0.04 \mathrm{~W} \mathrm{~m}^{-2}$, with a median value of $-0.22 \mathrm{~W}$ $\mathrm{m}^{-2}$. A more recent estimate of anthropogenic aerosol DRF by Myhre et al. (2013) is -0.27 (range: -0.58 to 
$-0.02) \mathrm{W} \mathrm{m}^{-2}$. In terms of the effects on cloud optical properties, the median estimate of cloud albedo forcing $(\mathrm{CAF})$ is $-0.70 \mathrm{~W} \mathrm{~m}^{-2}$, according to the 4 th assessment report of the Intergovernmental Panel on Climate Change (IPCC AR4) (Forster et al. 2007), but the uncertainty range is quite large, between -1.8 and $-0.3 \mathrm{~W} \mathrm{~m}^{-2}$. The more recent work by Yu et al. (2013) reports a similar range of -1.76 to $-0.17 \mathrm{~W} \mathrm{~m}^{-2}$.

There are 2 distinct differences in the RF between short-lived aerosols and long-lived greenhouse gases (GHGs). (1) Anthropogenic aerosol RF shows distinct regional features dominated by large values over mid-latitude land areas of the Northern Hemisphere. (2) While the concentration of GHGs and the associated warming are likely to continue in the next few decades (Moss et al. 2010), the aerosol loadings (and thus the magnitude of cooling) are likely to fluctuate subject to changes in regional aerosol precursor emissions, which depend highly on economic development. The stricter energy and environmental policies since the mid-1980s (Bond et al. 2007, Folini \& Wild 2011) have resulted in a decrease in atmospheric loading for some anthropogenic aerosols over Europe and North America. In contrast, China is in a period of rapid development in terms of industry and agriculture, which demands increasing levels of fossil fuel consumption and biomass burning. Indeed, observations in Eastern China have revealed continued increases in anthropogenic aerosol emissions and their loadings (Smith et al. 2011, Wang et al. 2011). Furthermore, transportation of air pollution takes the heavy aerosol loading of Eastern China and extends it in an easterly direction to other East Asian regions and neighboring oceans. In addition, high anthropogenic aerosol emissions over China are likely to persist into the next several decades under some future scenarios (Moss et al. 2010). The heavy anthropogenic aerosol loading in East Asia may have caused significant effects on regional climate (Menon et al. 2002, Qian et al. 2009, Li et al. 2011). Further, these spatial differences of aerosol emissions and loading may induce a latitudinal change in anthropogenic aerosol RF in the Northern Hemisphere, which may affect the pattern of global radiation budget to some degree. To further quantify how aerosols affect regional climate, it is therefore essential for the community to investigate anthropogenic aerosol RF and its possible time evolution over East Asia.

Previous studies (Myhre et al. 2001, Takemura et al. 2006) have investigated the historical variation of global mean aerosol RF. Skeie et al. (2011) used the historical emissions provided by Phase 5 of the Coupled Model Intercomparison Project (CMIP5) (Taylor et al. 2012) to examine global and some regional time series of aerosol RF from the PI to the present day. More recently, Bellouin et al. (2011), Takemura (2012), and Shindell et al. (2013) estimated future global and regional changes in aerosol RF using the Representative Concentration Pathway (RCP) scenarios. However, quantitative analyses on aerosol RF in East Asia are lacking. Moreover, calculating aerosol RF in climate models is also sensitive to some meteorological conditions, especially atmospheric moisture, of which significant differences exist between East Asia, North America and Europe; for example, the strong summer monsoon in East Asia (Wang 2006). Atmospheric relative humidity (RH) is an important factor in determining aerosol DRF for some hydrophilic species. Studies by Haywood \& Ramaswamy (1998), Adams et al. (2001), and Ocko et al. (2012) have demonstrated that atmospheric RH significantly affects the optical properties of hydrophilic aerosols, and the calculated DRF is also very sensitive to the modeled RH in climate models. During the summer monsoon period, atmospheric moisture is high over East Asia, producing favorable conditions for hygroscopic effects in hydrophilic aerosols. However, few researchers have investigated the effects of RH on the regional aerosol DRF and its time evolution over East Asia in the context of comparisons with Europe and North America. Zhou et al. (2012) suggested that the meteorological fields simulated by different climate models can be very different, and can therefore cause differences in aerosol RF estimates. In fact, these simulation biases of meteorological conditions in climate models are unavoidable, and they are also important sources of uncertainty in estimating aerosol RF. Therefore, further investigation of the relationship between regional aerosol RF and atmospheric moisture is warranted.

The aim of our study is to investigate aerosol DRF, indirect $\mathrm{CAF}$, and their time evolution at both global and regional scales using our global atmospheric general circulation model (AGCM) and its built-in radiative transfer model. The input aerosol dataset is simulated from NCAR CAM-Chem (Lamarque et al. 2012), covering the period 1850 to 2100. Although our analyses focus on East Asia, comparisons with other major industrial regions are also conducted. The possible effects of atmospheric moisture and associated model biases on aerosol DRF are examined. The aerosol species considered here are mainly from anthropogenic activities, including black carbon (BC), nitrate, organic carbon (OC), and sulfate. Dust and sea-salt are generally linked to natural sources, and therefore not considered for their DRF. 


\section{STUDY CONFIGURATIONS}

Calculating aerosol RF requires global datasets of aerosol distributions and meteorological fields (temperature, moisture, clouds, etc.) as inputs for atmospheric radiative transfer calculations. In the present study, we adopt the aerosol mass dataset simulations from NCAR CAM-Chem (Lamarque et al. 2012) and use the meteorology simulated from the AGCM developed at the State Key Laboratory of Numerical Modeling for Atmospheric Sciences and Geophysical Fluid Dynamics (LASG), Institute of Atmospheric Physics, Chinese Academy of Science (Bao et al. 2010). The model has 26 vertical hybrid layers, and its horizontal resolution is approximately $2.81^{\circ} \times$ $1.67^{\circ}$ in longitude and latitude. The model is able to capture mean large-scale climatological patterns and their variability, and has been used in various studies (e.g. Wu et al. 2012, He et al. 2013). More details can be found in the Supplement at www.int-res.com/ articles/suppl/c061p241_supp.pdf. Below, we present information directly related to the aerosol RF calculations of the model.

\subsection{Radiative transfer scheme}

The radiative transfer scheme used in the model is a modified version of the Edwards-Slingo scheme (Edwards \& Slingo 1996, Sun 2011), and uses an approach of correlated-k distribution (Fu \& Liou 1992, Li \& Barker 2005) for the flux calculation. The scheme has 9 spectral intervals for solar radiation (0.25 to $5.0 \mu \mathrm{m})$ and 8 for thermal radiation $(5.0$ to $40 \mu \mathrm{m})$. When compared with line-by-line calculations, the scheme can accurately simulate gaseous absorption due to water vapor, carbon dioxide, ozone, methane, nitrous oxide, oxygen and chlorofluorocarbons (Sun $2008,2011)$. The treatment of liquid cloud optical properties adopts the works of $\mathrm{Hu} \&$ Stamnes (1993) and Sun \& Rikus (2004), and the ice cloud properties follow the work of Chou (2002).

\subsection{Aerosol optical properties}

The NCAR aerosol dataset documented in Lamarque et al. (2012) includes the bulk mass of anthropogenic aerosol species of $\mathrm{BC}$, nitrate, $\mathrm{OC}$, and sulfate. To calculate aerosol optical properties, we follow the NCAR original study (Lamarque et al. 2012) and also refer to some previous relevant work (e.g. Kiehl et al. 2000, Liao et al. 2003) to choose the aerosol size parameters. The sources of the refractive indices used in our study are Toon et al. (1976) for ammonium sulfate; Haywood \& Ramaswamy (1998) for soot; and Hess et al. (1998) for 'water soluble' OC. The specific mass extinction, single-scattering albedo, and asymmetry factor of aerosols are then calculated by Mie theory. These radiative properties at $0.55 \mu \mathrm{m}$ are listed in Table 1 . While BC is treated as a dry aerosol, hygroscopic growth of hydrophilic sulfate and OC are considered, respectively, using the approach of Li et al. (2001) and Hess et al. (1998). Nitrate optical properties and their hygroscopic growth are treated the same as sulfate. External mixing is adopted for these aerosols.

\subsection{Aerosol-cloud interactions}

To study the aerosol CAF, there are many schemes that explicitly consider the interactions between aerosol and cloud droplet number concentration (CDNC) (e.g. Abdul-Razzak \& Ghan 2002, Nenes \& Seinfeld 2003). However, considering the large uncertainties in the present understanding of many aerosol-cloud interactions and their parameterizations in climate models (Ekman 2014), for illustrative purposes, we adopt the widely-used empirical approach of Boucher \& Lohmann (1995) and Quaas et al. (2006) to link CDNC $\left(N_{\mathrm{di}} \mathrm{cm}^{-3}\right)$ to aerosol mass concentration $\left(m_{\text {aeri }} \mu \mathrm{g} \mathrm{m}^{-3}\right)$ :

$$
N_{\mathrm{d}}=\exp \left(a_{0}+a_{1} \ln m_{\text {aer }}\right)
$$

Here, $a_{0}(=5.1)$ and $a_{1}(=0.41)$, derived from in situ measurements, account for the total mass of all potential hydrophilic aerosols, including sub-micron sea salt $(0.2$ to $1.0 \mu \mathrm{m})$, sulfate, and primary and secondary organic aerosols. The cloud droplet effective radius $\left(r_{\mathrm{e}} \mu \mathrm{m}\right)$ for warm clouds can then be calculated using a diagnostic scheme (Martin et al. 1994):

Table 1. Physical and optical properties at $0.55 \mu \mathrm{m}$ assumed for dry aerosols. $r_{\mathrm{g}}$ : geometric radius $(\mu \mathrm{m}) ; \sigma$ : standard deviation; $\rho$ : mass density $\left(\mathrm{g} \mathrm{cm}^{-3}\right) ; \sigma_{\mathrm{e}}$ : extinction coefficient $\left(\mathrm{m}^{2} \mathrm{~g}^{-1}\right) ; \omega$ : single-scattering albedo; $g$ : asymmetry factor

\begin{tabular}{|lcccccccc|}
\hline $\begin{array}{l}\text { Aerosol } \\
\text { component }\end{array}$ & Refractive index & $r_{\mathrm{g}}$ & $\sigma$ & $\rho$ & $\sigma_{\mathrm{e}}$ & $\omega$ & $g$ \\
\hline Sulfate & $1.53-1.0 \times 10^{-7} \mathrm{i}$ & 0.05 & 2.0 & 1.769 & 3.41 & 1.0 & 0.64 \\
BC & $1.75-0.44 i$ & 0.0118 & 2.0 & 1.0 & 9.26 & 0.21 & 0.34 \\
OC & $1.53-0.006 i$ & 0.0212 & 2.0 & 1.8 & 2.91 & 0.96 & 0.61 \\
\hline
\end{tabular}




$$
r_{\mathrm{e}}=\left(\frac{3 L}{4 \pi \rho_{\mathrm{w}} k N_{\mathrm{d}}}\right)^{1 / 3}
$$

where $L$ is cloud water content, $\rho_{\mathrm{w}}$ is the density of water, and $k$ is a modification coefficient ( 0.67 over continents and 0.8 over oceans) to account for the difference between the mean volume radius and $r_{\mathrm{e}}$. The treatments thus link the aerosol mass directly to cloud bulk radiative properties for CAF calculations. It should be noted that the empirical scheme used in our work is derived from limited observational sites and is not globally representative. In addition, the empirical scheme based on the present observational period may not be suitable for past or future climate conditions.

\subsection{Aerosol distributions}

To calculate the aerosol DRF and CAF, we use a prescribed aerosol dataset simulated from an atmospheric chemical-transport model. This method avoids time-consuming interactive aerosol processes and has been used in many studies (e.g. Kiehl et al. 2000, Skeie et al. 2011). Here, we use the decadal aerosol mass dataset simulated from NCAR CAM-Chem (Lamarque et al. 2012), which includes sulfate, BC, OC, nitrate, dust, and sea-salt. The historical period covered is 1850 to 2009 , and the future period is 2010 to 2109. The future aerosol distribution is based on the CMIP5 mid-range (RCP4.5) and high-range
(RCP8.5) scenarios (Moss et al. 2010). These 2 scenarios are the core scenarios in the CMIP5 experiments (Taylor et al. 2012) and are representative of future climate change. The decadal average of $1850-1859$ is treated as the PI. The historical and future GHG concentrations and RFs are taken from the CMIP5 RCP website (www.iiasa.ac.at/web-apps/tnt/RcpDb).

Fig. 1 presents the temporal change in anthropogenic sulfate and BC atmospheric loading and their aerosol optical depth (AOD). Here, the AOD is the averaged value for the shortwave band ( 0.50 to $0.625 \mu \mathrm{m})$ calculated in our work. The global mean sulfate and $\mathrm{BC}$ loadings begin to increase from the PI, and peak in the 1980s (maximum: $2.34 \mathrm{mg} \mathrm{m}^{-2}$ ) and 1990s $\left(0.15 \mathrm{mg} \mathrm{m}^{-2}\right)$, respectively. The sulfate and $\mathrm{BC}$ loadings over Europe and North America reach maximum values earlier than in East Asia, and are then projected to continuously decrease to the PI level by the end of the 21st century. In the second half of the 21st century, the projected BC loading in Europe and North America is even below the PI level. In contrast, the sulfate and BC loading in East Asia peak in the 2010s, with values of 10.89 and 1.08 $\mathrm{mg} \mathrm{m}^{-2}$ for RCP4.5, respectively. In particular, the projected BC loading in East Asia is much higher than the global mean and the other 2 regions. Under RCP8.5, the future sulfate and BC loading over East Asia are slightly higher than under RCP4.5. However, the 2 aerosol loadings over Europe and North America are relatively lower under RCP8.5, which is
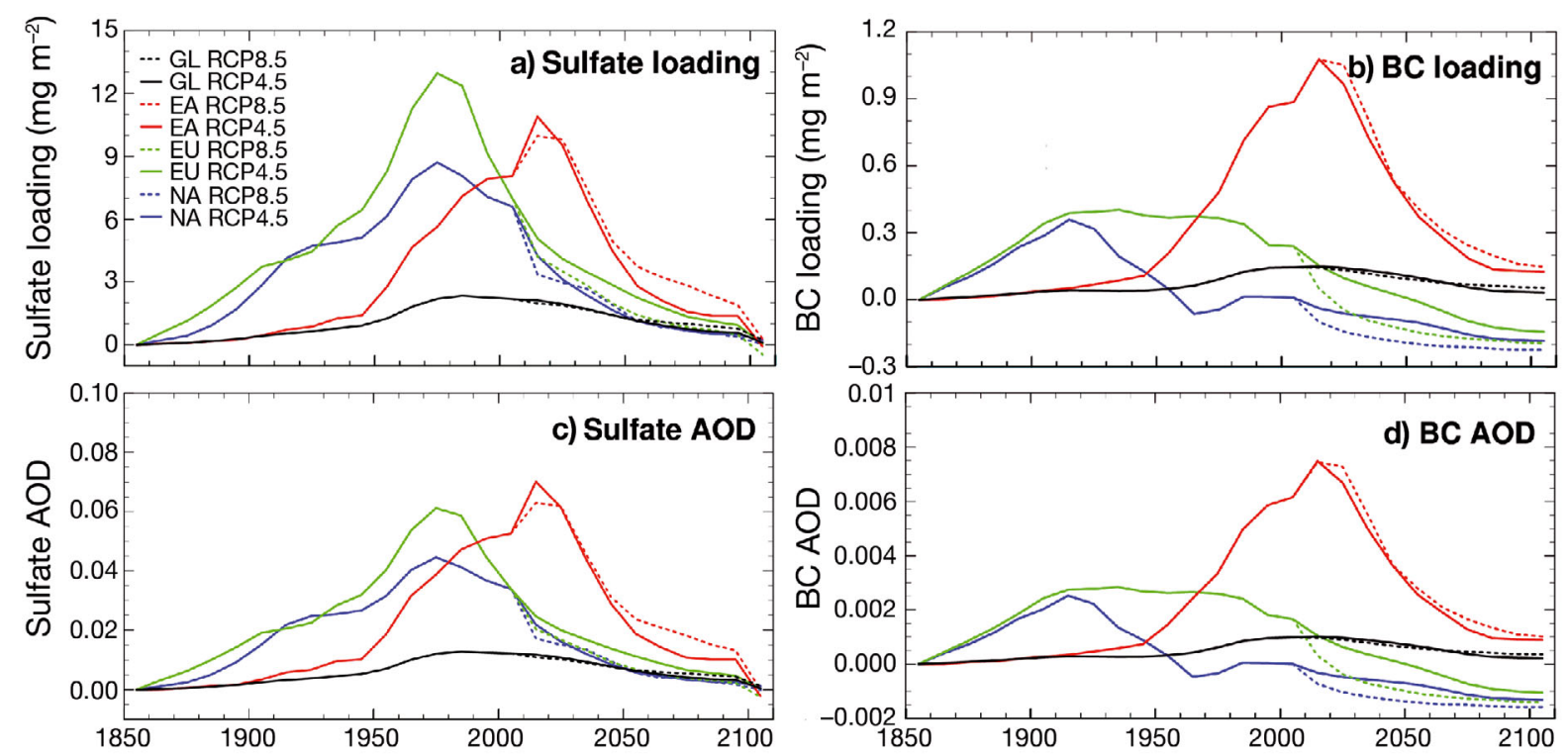

Fig. 1. Annual mean (a) sulfate and (b) black carbon (BC) loadings ( $\mathrm{mg} \mathrm{m}^{-2}$ ), (c) sulfate and (d) BC aerosol optical depths (AOD) relative to pre-industrial values. The 3 major industrial regions are Europe (EU) $\left(35^{\circ}-60^{\circ} \mathrm{N}, 0^{\circ}-45^{\circ} \mathrm{E}\right)$, East Asia $(\mathrm{EA})$ $\left(20^{\circ}-45^{\circ} \mathrm{N}, 100^{\circ}-145^{\circ} \mathrm{E}\right)$, and North America (NA) $\left(25^{\circ}-50^{\circ} \mathrm{N}, 245^{\circ}-290^{\circ} \mathrm{E}\right)$. GL: global mean. Since 2010, solid lines $=\mathrm{RCP} 4.5$ scenario and dashed lines $=$ RCP8.5 scenario 
likely due to much stricter emission control polices in the 2 regions. Similar features associated with aerosol emissions and loadings under different RCPs were also reported by Bellouin et al. (2011) and Takemura (2012). Our results indicate that anthropogenic aerosols from East Asia are projected to be bigger contributors to global aerosol loading, as compared to European and North American regions, especially under the high-range RCP8.5 scenario. Additionally, as shown in Fig. 1, the variation of sulfate AOD (Fig. 1c) is similar to its variation in loading, but an evident difference is that the largest AOD appears over East Asia in the 2010s. Sulfate AOD is highly affected by simulated RH. The annual mean atmospheric precipitable water over East Asia is much larger than that over Europe (see Table 3). Thus, the sulfate hygroscopic effect is stronger and causes higher AOD when sulfate loading over East Asia peaks in the 2010s. BC in this study is treated as a dry species, and is thus unaffected by RH. The temporal change of BC AOD (Fig. 1d) is therefore consistent with its loading, and the maximum value also exists over East Asia in the 2010s.

\subsection{RF calculation}

We use the 'instantaneous RF' (Forster et al. 2007) to calculate aerosol RF. The radiation code is called twice to calculate aerosol RF in our AGCM run. For DRF, the first call performs a standard calculation without aerosol species. The second call includes the specified aerosol species in a diagnostic mode, i.e. the aerosols only affect the radiative process without influencing the model simulation. The radiative flux difference at the TOA or surface between the 2 radiation calls is defined as the aerosol DRF. Similarly, the DRF due to aerosols in the whole atmosphere is also calculated. For CAF, the CDNC and effective cloud drop radius is firstly diagnosed in the first radiation call using the aerosol mass in the PI (1850 to 1859). The second call uses a different decadal aerosol mass. The difference of radiative flux at the TOA and the surface between the PI and the next decadal results is computed as CAF relative to the PI. The AGCM is run to a stable state and then integrated for a period of 1 yr to calculate monthly mean aerosol RFs. In our study, the input for radiative processes uses the same state variables, except for aerosol. These state variables include simulated air temperature, water vapor, surface conditions, cloud fraction, and water content. The greenhouse gases and solar forcing are fixed at the present level.
Meanwhile, the ozone profiles are climatological results from Li \& Shine (1995). The sea surface temperature and sea ice are taken from the prescribed Atmospheric Model Inter-comparison Project (AMIP) climatology. Thus, the meteorological variables are the same for the time series of historical and futureprojected aerosol RF.

\section{RESULTS}

\subsection{Geographical distribution of aerosol RF}

First, we present the global distribution of aerosol effects in the most recent decade (2000 to 2009) relative to the PI. As expected, the largest change in AOD exists over Eastern China (Fig. 2a) caused by the presence of the strongest sulfate and BC loading. The distribution of aerosol DRF (Fig. 2b) basically reflects the AOD pattern. However, the CAF pattern (Fig. 2d) is somewhat different from the CDNC distribution (Fig. 2c) due to the effects of cloud distribution. For example, the weaker CAF in central Asia can be attributed to the lower cloud amount and water content even though the CDNC is not small. In addition to Eastern China, stronger CAF is also present in regions with heavy aerosol loading, such as the Asian maritime continent, tropical western Africa, and Central America, where marine stratocumulus clouds are persistent (Ming et al. 2005). The global annual mean TOA aerosol DRF in the 2000s relative to the PI is calculated to be $-0.27 \mathrm{~W} \mathrm{~m}^{-2}$ for all-sky and $-0.63 \mathrm{~W} \mathrm{~m}^{-2}$ for clear-sky conditions. As seen in Table 2, the anthropogenic aerosol DRFs in both allsky and clear-sky conditions are close to the multimodel means from Aerosol Comparisons between Observations and Models (AeroCom) I and II. The calculated AOD and the clear-sky normalized DRF (NDRF) are also within the AeroCom range of values. Our AOD is slightly weaker than the AeroCom model mean because we use AOD from the interval of 0.50 to $0.625 \mu \mathrm{m}$ rather than at $0.55 \mu \mathrm{m}$, which results in lower AOD and higher NDRF. The CAF value of $-0.67 \mathrm{~W} \mathrm{~m}^{-2}$ is also very close to the mean of $-0.70 \mathrm{~W} \mathrm{~m}^{-2}$ reported by Forster et al. (2007). Moreover, much larger values are obtained in the industrialized regions. For example, the maximum aerosol DRF and CAF over East Asia are up to -1.0 and $-3.0 \mathrm{~W} \mathrm{~m}^{-2}$, respectively.

The decadal changes in the global distribution of aerosol RF for several decades at the TOA and surface as well as in the atmosphere using RCP4.5 are depicted in Fig. 3. For the 1980s, the TOA global 
a) $A O D$

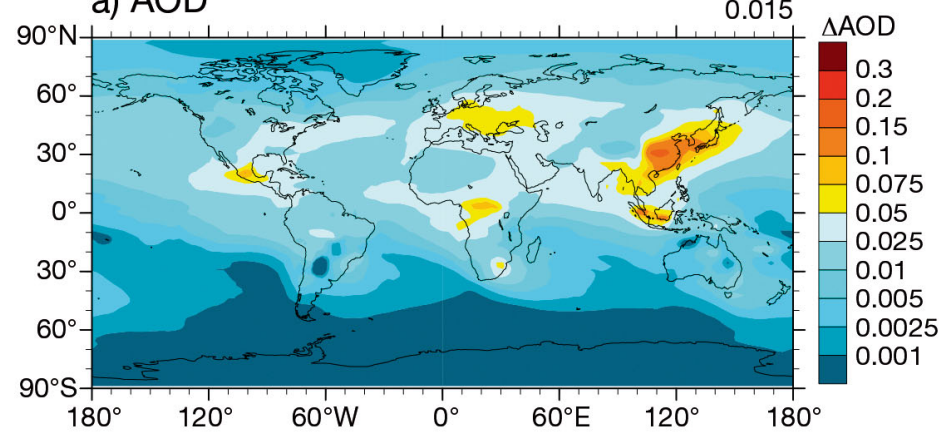

c) CDNC

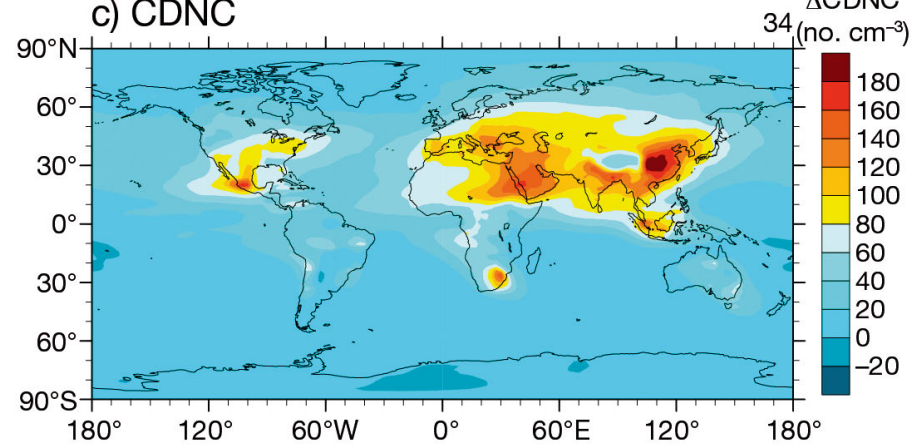

b) TOA DRF
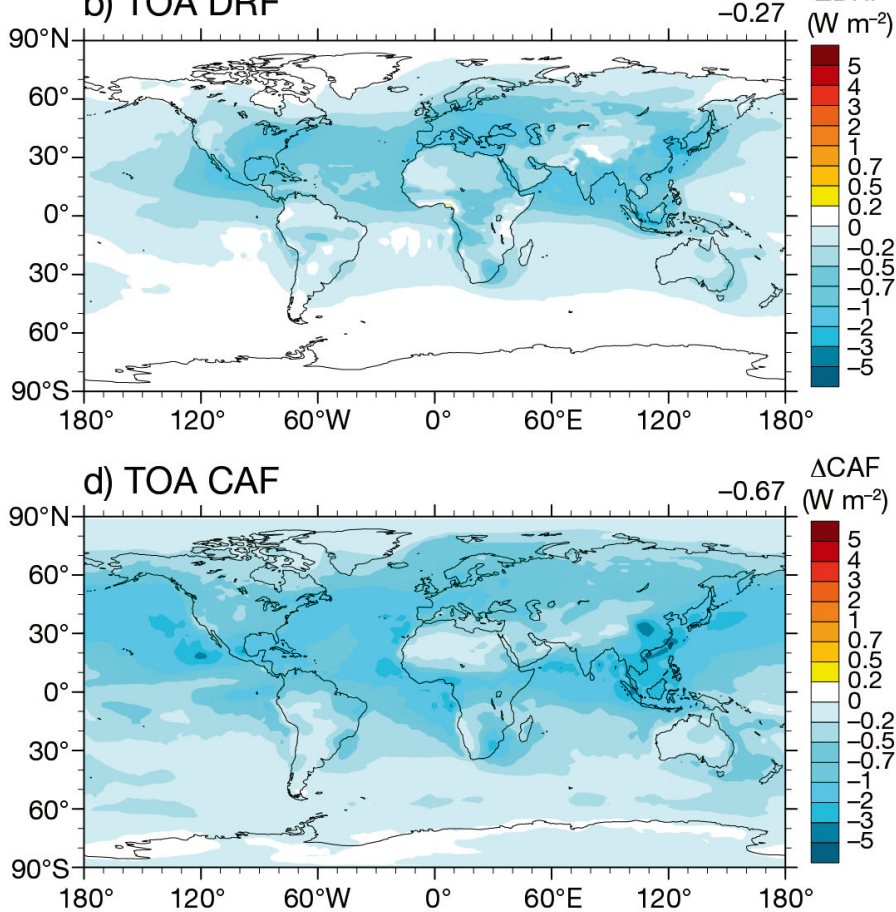

Fig. 2. Geographical distribution of (2000-2009, relative to the pre-industrial value) annual mean (a) aerosol optical depth (AOD), (b) aerosol direct radiative forcing (DRF) $\left(\mathrm{W} \mathrm{m}^{-2}\right)$ at the all-sky top of the atmosphere (TOA), (c) cloud droplet number concentration $\left(\mathrm{CDNC}_{\text {; droplets }} \mathrm{cm}^{-3}\right)$ at $\sim 850 \mathrm{hPa}$, and (d) cloud albedo forcing (CAF) (W m${ }^{-2}$ ). Values at top right: global means

mean DRF (versus PI) is calculated to be $-0.30 \mathrm{~W} \mathrm{~m}^{-2}$ with strong negative forcing occurring over Central and Northeast America, Europe and East Asia. Changes in the aerosol DRF at the TOA and surface in the 2000s (relative to the 1980s) decreases remarkably over Europe and North America and may continue to decrease until the $2030 \mathrm{~s}$, almost up to $2.0 \mathrm{~W}$ $\mathrm{m}^{-2}$. This change is consistent with the surface brightening phenomena reported by some researchers (e.g. Wild 2009). The strong negative DRF over Eastern China and India persist until the 2030s, reflecting a continuous surface dimming feature. The CAF change is similar to aerosol DRF. In contrast to TOA cooling, the atmospheric DRF in the 1980s (relative to PI), as shown in Fig. 3, is positive over most regions, with a global average of $0.39 \mathrm{~W} \mathrm{~m}^{-2}$. The largest positive atmospheric DRF, up to $5.0 \mathrm{~W} \mathrm{~m}^{-2}$, occurs over Eastern China. Moreover, there are also negative changes in the atmospheric DRF over Northeast America and the British Isles, which is caused by the reduction of $\mathrm{BC}$ loading. The strong positive atmospheric DRF over Asian regions may persist until the 2030s, while the atmospheric DRF over North America and Europe becomes much weaker.

\subsection{Decadal variation of global mean aerosol RF}

Fig. 4 shows the decadal changes (relative to PI) in the annual, global and regional mean DRF due to anthropogenic aerosols. The global mean all-sky $\mathrm{DRF}$ at the TOA reaches a maximum of $-0.30 \mathrm{Wm}^{-2}$ in the 1980s and decreases thereafter. The global mean all-sky surface DRF peaks in the 1990s with a value of $-0.73 \mathrm{~W} \mathrm{~m}^{-2}$, and the atmospheric all-sky DRF peaks in the 2010s for RCP4.5 with a value of $0.48 \mathrm{~W} \mathrm{~m}^{-2}$. Comparatively, the regional mean DRFs are much larger than the global average but peak in different periods because of different temporal variations of individual aerosol loadings. Note that, because of the dominance of sulfate aerosols, the change in DRF at the TOA is similar to that of sulfate loading. The TOA DRF over Europe and North America reaches a maximum in the 1980 s, but the largest DRF over East Asia occurs under RCP4.5 in the 2010s. On the other hand, the atmospheric DRF coincides with variation of BC loading (Fig. 4e). The clear-sky atmospheric DRF (not shown) is very close to the all-sky result. Because of $\mathrm{BC}$ absorption in the atmosphere, the surface DRF is stronger than the TOA DRF (Fig. 4c). The strongest surface and atmo- 
Table 2. Global mean anthropogenic values for all-sky and clear-sky aerosol direct radiative forcing (DRF), normalized DRF (NDRF) with respect to aerosol optical depth (AOD) for clear sky, and present day total cloud fraction. For this study, AOD is the mean value in 0.50 to $0.625 \mu \mathrm{m}$. Parentheses: AeroCom multi-models range

\begin{tabular}{|lccccc|}
\hline & $\begin{array}{c}\text { All-sky DRF } \\
\left(\mathrm{W} \mathrm{m}^{-2}\right)\end{array}$ & $\begin{array}{c}\text { Clear-sky DRF } \\
\left(\mathrm{W} \mathrm{m}^{-2}\right)\end{array}$ & $\begin{array}{c}\text { Clear-sky NDRF } \\
\left(\mathrm{W} \mathrm{m}^{-2}\right)\end{array}$ & $\begin{array}{c}\text { AOD } \\
\text { Total cloud } \\
\text { fraction }\end{array}$ \\
\hline AeroCom I (Schulz et al. 2006) & -0.22 & -0.68 & -23 & 0.029 & 0.63 \\
& $(-0.41$ to 0.04$)$ & $(-0.94$ to -0.29$)$ & $(-33$ to -10$)$ & $(0.014$ to 0.046$)$ & $(0.57$ to 0.70$)$ \\
AeroCom II (Myhre et al. 2013) & -0.27 & -0.67 & -26.8 & 0.0295 & 0.57 \\
& $(-0.58$ to -0.02$)$ & $(-1.01$ to -0.35$)$ & $(-76$ to -17.4$)$ & $(0.0099$ to 0.0527$)$ & $(0.25$ to 0.66$)$ \\
This study & -0.27 & -0.63 & -40.35 & 0.0155 & 0.6 \\
\hline
\end{tabular}

spheric DRF occur over East Asia, with values of -4.48 and $3.20 \mathrm{~W} \mathrm{~m}^{-2}$, respectively, under the RCP4.5 scenario in the 2010s.

By the end of the 21st century, the aerosol DRF over Europe and North America is projected to decrease below the PI level. In particular, the rapidly deceasing $\mathrm{BC}$ loading in the 2 regions results in a weaker atmospheric DRF from the middle of the 21st century with respect to the PI. In contrast, the stronger DRF over East Asia could last several decades until the 2030s, thus implying that anthropogenic aerosol forcing in the near future is projected to be increasingly important over East Asia. As shown in Fig. 4b,d, the DRF at the TOA and surface are much larger in the absence of clouds. Under RCP4.5 in the 2010s, the maximum TOA DRF over East Asia increases from about $-1.29 \mathrm{~W} \mathrm{~m}^{-2}$ under all-sky conditions to $-3.51 \mathrm{~W} \mathrm{~m}^{-2}$ under clear-sky conditions, and the corresponding maximum European value in the 1970s increases from -2.10 to $-3.35 \mathrm{~W} \mathrm{~m}^{-2}$. The clear-sky TOA DRF depends on the aerosol loading and, more importantly, on atmospheric moisture, as shown in Table 3, which has large values over East Asia. As a result, the hygroscopic effects, mainly due to watersoluble sulfate aerosols, lead to larger clear-sky DRF over East Asia. As listed in Table 3, the sulfate DRF normalized by mass loading to exclude the loading effect over East Asia is therefore considerably larger than the regional mean over Europe. Similar to the variation of $\mathrm{BC}$ and sulfate loading, the future aerosol DRF for RCP8.5 over East Asia is slightly stronger than that for RCP 4.5 and is projected to contribute more DRF compared to the 2 other regions.

Fig. 5 shows the variation of decadal mean global and regional aerosol indirect RF. The 850-hPa CDNC change from the PI to the late 20th century shows the same increasing trend as the sulfate loading. The biggest CDNC change occurs in the European region in the 1970s, and the second largest change in CDNC happens in East Asia in the 2010s. According to the empirical relationship, the increase of CDNC will reduce the effective radius of the warm cloud $\left(r_{\mathrm{e}}\right)$ if the cloud water content and other meteorological fields are fixed. As presented in Fig. 5b, $r_{\mathrm{e}}$ continuously decreases while the CDNC increases in Europe until the 1970s; similarly, the averaged $r_{\mathrm{e}}$ over East Asia decreases until the 2010s. The largest $r_{\mathrm{e}}$ change of $0.338 \mu \mathrm{m}$ over East Asia under RCP4.5 in the 2010s is slightly larger than the change of $0.324 \mu \mathrm{m}$ over Europe because the cloud water content over the former is stronger than the latter. However, the projected $r_{\mathrm{e}}$ over East Asia is $0.323 \mu \mathrm{m}$ under RCP8.5 in the 2010s, which shows that the projected regional $\mathrm{CAF}$ is also very sensitive to the aerosol loading. As shown in Fig. 5C, the temporal change of global annual average CAF is very similar to the TOA DRF, but the global mean maximum of $-0.67 \mathrm{~W} \mathrm{~m}^{-2}$ occurs in the 2000s. The CAF peak over East Asia is about 4 decades later than in the European and North American regions. Moreover, the CAF peaks are -2.13 and $-2.01 \mathrm{~W} \mathrm{~m}^{-2}$ over East Asia for RCP4.5 and RCP8.5, respectively, which are twice as high as the 1970s peak of $-1.0 \mathrm{~W} \mathrm{~m}^{-2}$ over Europe (Fig. 5c).

As also pointed out by Skeie et al. (2011) and Lamarque et al. (2011), starting in the 1970s, the sulfate and BC loading centers in the Northern Hemisphere begin to move southward, which most likely affects the aerosol DRF and CAF distribution because of the difference in the climate regimes between the tropical and mid-latitudes. Fig. 6 shows the latitudetime evolution of aerosol RF. The strong TOA DRF around $40^{\circ} \mathrm{N}$ begins to decrease, and the peak position moves southward to the low latitudes from the 1980s (Fig. 6a). For the atmosphere (Fig. 6b), there are 2 periods with stronger positive DRF: one in the early 20th century over $45^{\circ} \mathrm{N}$, with a large BC loading in the United States and British Isles; and another from the 1980 s to 2050 s at $30^{\circ} \mathrm{N}$, mainly caused by the strong BC loading in Asia. Meanwhile, there is also a large positive DRF over the tropical regions. Fig. $6 \mathrm{c}$ shows that the negative surface DRF is stronger than TOA DRF, and its peak period is also 


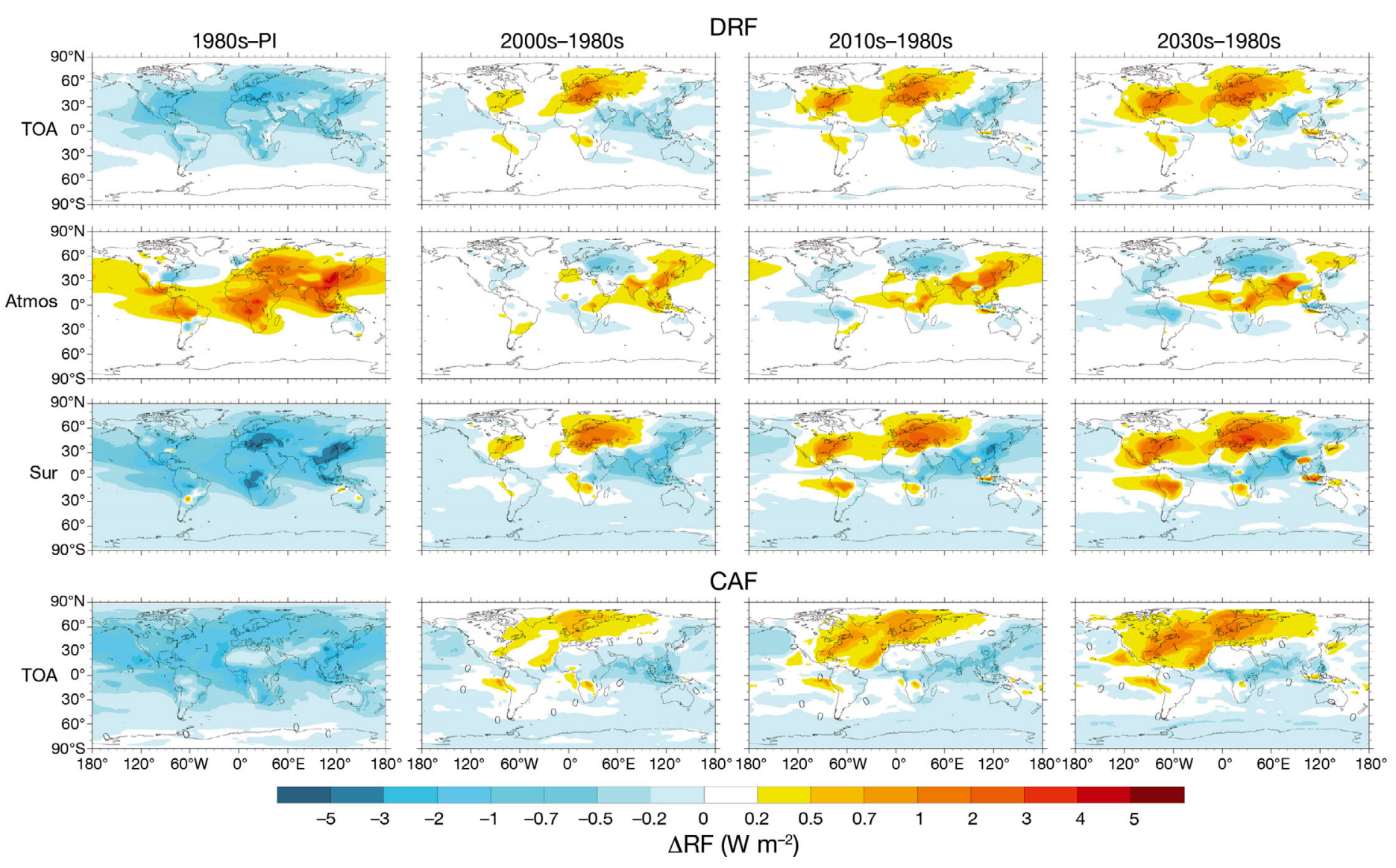

Fig. 3. Geographical distribution of annual mean change in aerosol all-sky RF under RCP4.5. Rows 1 to 3: TOA DRF, atmospheric absorption and surface DRF, respectively. Row 4: CAF at the TOA. Column 1: 1980s relative to PI. Columns 1 to 4 : 2000s, 2010s and 2030s relative to the 1980s, respectively. Values at top right: global means. See Fig. 2 for acronyms

later than at the TOA but earlier than the atmosphere. For CAF (Fig. 6d), the southward shifting is more evident than in the DRF. The shift begins in the 1970s, and the forcing peak could remain at a high level until the 2040s. It is noted that the strong aerosol RF can persist over 5 decades in the lower latitudes of the Northern Hemisphere. Additionally, although the evolution pattern under RCP8.5 is similar to RCP4.5, the projected aerosol RF in low latitudes could persist longer. This indicates that-under a higher scenario - low latitudes (especially East Asia) are projected to contribute more to anthropogenic aerosol RF in the next decades. With the change of aerosol RF to low latitudes, the spatial pattern of radiative energy budget at TOA may be somewhat perturbed. In this way, the change in East Asian aerosol RF likely imposes larger climate impacts, and more attention should be paid to this in the future.

The maximum values and the corresponding periods of aerosol RF (relative to the PI) are summarized in Table 4 for the globe and several regions. The global aerosol RF at the TOA peaks in the 1980s, which is consistent with the conclusion by Shindell et al. (2013), but the surface DRF, atmospheric DRF, and CAF have different peak periods with respect to the TOA DRF. The combined aerosol RF (DRF and CAF) peaks over Europe and North America around the 1970 s with a magnitude of up to $-2.0 \mathrm{~W} \mathrm{~m}^{-2}$. Both aerosol DRF and CAF in East Asia peak under the RCP4.5 scenario in the 2010 s with much larger maximum values than the global averages, indicating that aerosols will exert strong forcing on the regional climate system. Since the aerosol RF is substantial, we further compare its magnitude with the warming forcing due to the major GHGs including $\mathrm{CO}_{2}, \mathrm{CH}_{4}$, $\mathrm{N}_{2} \mathrm{O}, \mathrm{HFCs}, \mathrm{PFCs}, \mathrm{SF} 6$, and Montreal Protocol gases. The decadal TOA DRF due to GHGs relative to the PI is calculated using the dataset from the CMIP5 website. During most periods, the warming TOA RF due to GHGs is much larger than the global mean values of combined aerosol RF (DRF and CAF), reaching $4.27 \mathrm{~W} \mathrm{~m}^{-2}$ for RCP4.5 and $7.84 \mathrm{~W} \mathrm{~m}^{-2}$ for RCP8.5 by the end of the 21st century (Fig. 7). However, it is totally different when examined over East Asia: the 

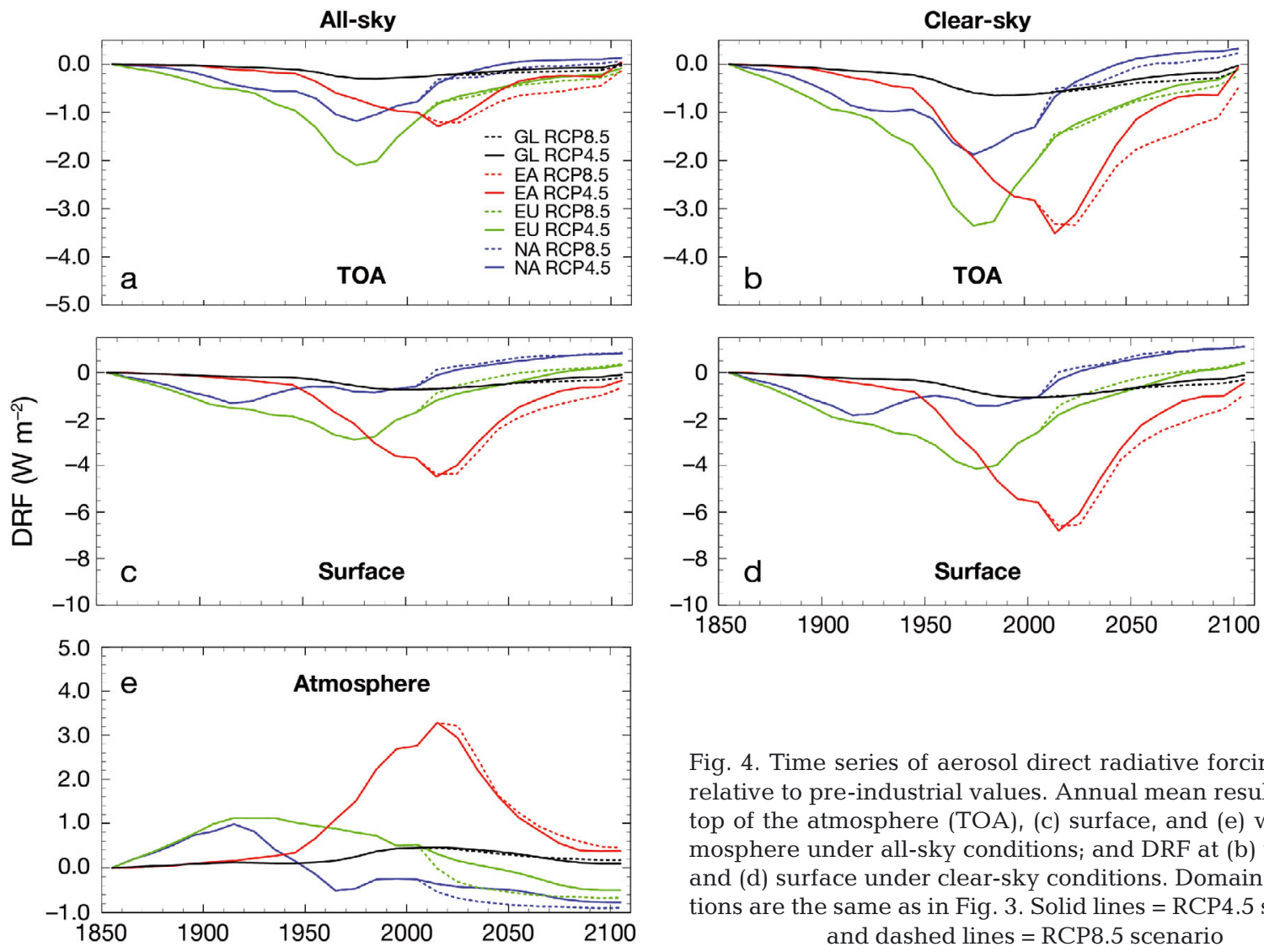

Fig. 4. Time series of aerosol direct radiative forcing (DRF) relative to pre-industrial values. Annual mean results for (a) top of the atmosphere (TOA), (c) surface, and (e) whole atmosphere under all-sky conditions; and DRF at (b) the TOA and (d) surface under clear-sky conditions. Domain descriptions are the same as in Fig. 3. Solid lines = RCP4.5 scenario, and dashed lines $=$ RCP8.5 scenario

Table 3. Annual mean meteorological variables simulated from our atmospheric general circulation model, aerosol loading in NCAR dataset, and sulfate direct radiative forcing (DRF) and normalized DRF (NDRF) by its loading and peak time (Global: 1980s; Europe: 1970s; East Asia: 2010s) in different regions. TOA: top of the atmosphere. Here, the projected value is for RCP4.5

\begin{tabular}{|c|c|c|c|c|c|c|c|c|c|}
\hline \multirow[b]{2}{*}{ Components } & \multirow{2}{*}{$\begin{array}{l}\text { Precipitatable } \\
\text { water }(\mathrm{mm})\end{array}$} & \multirow[t]{2}{*}{$\begin{array}{l}\text { Total cloud } \\
\text { amount }\end{array}$} & \multirow[t]{2}{*}{$\begin{array}{l}\text { Cloud water } \\
\text { path }\left(\mathrm{g} \mathrm{m}^{-2}\right)\end{array}$} & \multicolumn{2}{|c|}{$\begin{array}{c}\text { Total aerosol loading } \\
\left(\mathrm{mg} \mathrm{m}^{-2}\right)\end{array}$} & \multicolumn{2}{|c|}{$\begin{array}{l}\text { Sulfate DRF at TOA } \\
\qquad\left(\mathrm{W} \mathrm{m}^{-2}\right)\end{array}$} & \multicolumn{2}{|c|}{$\begin{array}{c}\text { Sulfate NDRF at } \\
\text { TOA }\left(\mathrm{W} \mathrm{g}^{-1}\right)\end{array}$} \\
\hline & & & & All aerosols & Sulfate & All-sky & Clear-sky & All-sky & Clear-sky \\
\hline Global & 27.05 & 0.6 & 97.44 & 2.92 & 2.34 & -0.39 & -0.66 & -168 & -280 \\
\hline Europe & 15.75 & 0.49 & 91.68 & 14.52 & 12.96 & -1.46 & -2.33 & -113 & -180 \\
\hline East Asia & 29.06 & 0.46 & 103.03 & 15.39 & 10.89 & -1.88 & -3.46 & -173 & -318 \\
\hline
\end{tabular}

combined aerosol RF is quite large, comparable to the warming RF due to GHG before the 2030s. For example, the combined aerosol RF value of $-3.42 \mathrm{~W}$ $\mathrm{m}^{-2}$ in the 2010s is even slightly larger than the corresponding GHG RF $\left(-3.28 \mathrm{~W} \mathrm{~m}^{-2}\right)$ in East Asia for RCP4.5. This implies that the aerosol cooling largely offsets the warming RF due to GHGs over East Asia in the first half of the 21st century. Of course, the present model estimation of aerosol RF in East Asia is still subject to very large uncertainties (Myhre et al. 2013). Some works (e.g. Chang \& Liao 2009) suggest the aerosol negative DRF might be even higher than our values in Eastern China. Considering the severe air pollution over China in recent years (Zhao et al. 2013), the actual aerosol RF in Eastern China may be much stronger than the estimation in this study, and levels are likely to persist in the near future.

\subsection{Sensitivity of aerosol DRF to atmospheric moisture}

In addition to atmospheric loading, the aerosol RF is also determined by many other factors, such as air moisture, cloud macro- and micro-physical properties, surface albedo, solar radiation and others. Of these 

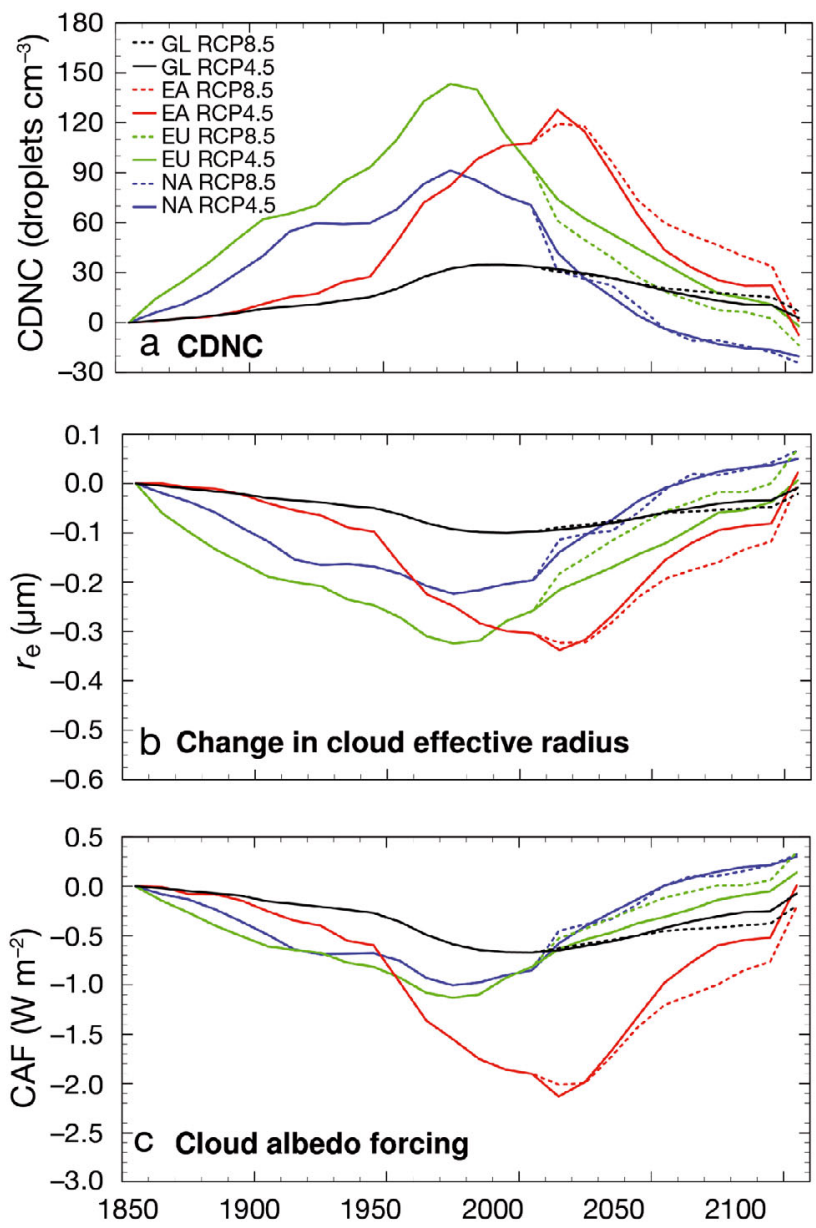

Fig. 5. Time series of (a) cloud droplet number concentration (CDNC; \# droplets $\mathrm{cm}^{-3}$ ) at $\sim 850 \mathrm{hPa}$, (b) change in cloud effective radius $\left(r_{\mathrm{e} i} \mu \mathrm{m}\right)$ at $\sim 850 \mathrm{hPa}$ and (c) aerosol cloud albedo forcing (CAF) from the 1860s to 2100 s relative to the $1850 \mathrm{~s}$

factors, air moisture (that affects the aerosol hygroscopic effects) has strong regional variation (Li et al. 2012). Here, we use sulfate aerosols as an example to examine the effect in different regions, especially under clear-sky conditions. The contrasting sulfate loading between the 1990s and 2000s show a decrease over Europe, but an increase over East Asia. The domains are the same as in section 3 .

The observational climatology of air moisture is derived from the ERA-Interim dataset (Uppala et al. 2008). As shown in Fig. 8a,b, the strongest observational air moisture occurs over East Asia in summer, when the heaviest sulfate loading also occurs (Fig. 8c,d). Thus, the higher air moisture over East Asia in summer provides a good setting for studying the hygroscopic effects of hydrophilic aerosols. The results, depicted in Fig. 9a,b, show that the strongest clear-sky DRF due to sulfate occurs over East Asia and coincides with maximum air moisture in August. This aspect becomes even clearer when we examine the normalized clear-sky DRF to exclude the effects of sulfate loading. Fig. 9c,d clearly show that the clear-sky sulfate NDRF in summer is the strongest over East Asia and the weakest over Europe, with North America between.

Since the calculated aerosol DRF depends on the realism of the simulated moisture, here we also discuss the uncertainty of DRF associated with the model biases. Compared to the observational RH (not shown), the model underestimates the RH in all 3 regions, although the biases are relatively larger over Europe than the other 2 regions. Consequently the hygroscopic effect is underestimated over Europe. In East Asia, the simulated air moisture is more accurate than Europe. Therefore, given the sulfate loading, the water uptake of sulfate will be relatively well simulated over East Asia, which leads to the stronger clear-sky DRF. This feature is more obvious in the 2000s (Fig. 9b), when the sulfate loading over East Asia is close to that over Europe (Fig. 8d). The results presented here indicate that estimating aerosol DRF in a climate model is very sensitive to the atmospheric moisture. Moreover, the work by Li et al. (2012) showed that the improvement of RH simulation could slightly increase AOD and DRF over Europe, but the effects of stronger summer climatological air moisture over East Asia play dominant roles in aerosol DRFas compared to this RH improvement, which therefore does not affect the results presented in Figs. 1 \& 9. The effects of cloud on aerosol DRF are also important. We do not further discuss associated all-sky issues here because of the complexity of cloud properties.

\subsection{Observational validation in East Asia}

Due to sparse in situ aerosol observations over China, there are few observational comparisons for aerosol mass concentration, which add further difficulties in estimating aerosol RF in East Asia, as well as the aforementioned effects of air moisture. Here, we use surface mass density from the Chinese aerosol network (Zhang et al. 2012) to validate the simulation of BC and sulfate mass. These dataset are from 14 sites from 2006 to 2007 and have been averaged into annual mean results. Fig. 10 shows the scatter relationship between simulations and observations for $\mathrm{BC}$ and sulfate aerosols. It is clearly seen that simulated BC and sulfate surface concentrations are even less than half of the corresponding observations 


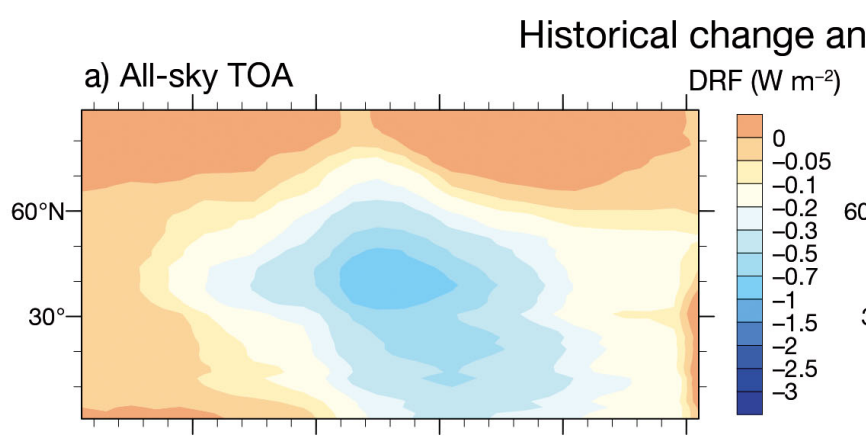

Historical change and RCP4.5 projection
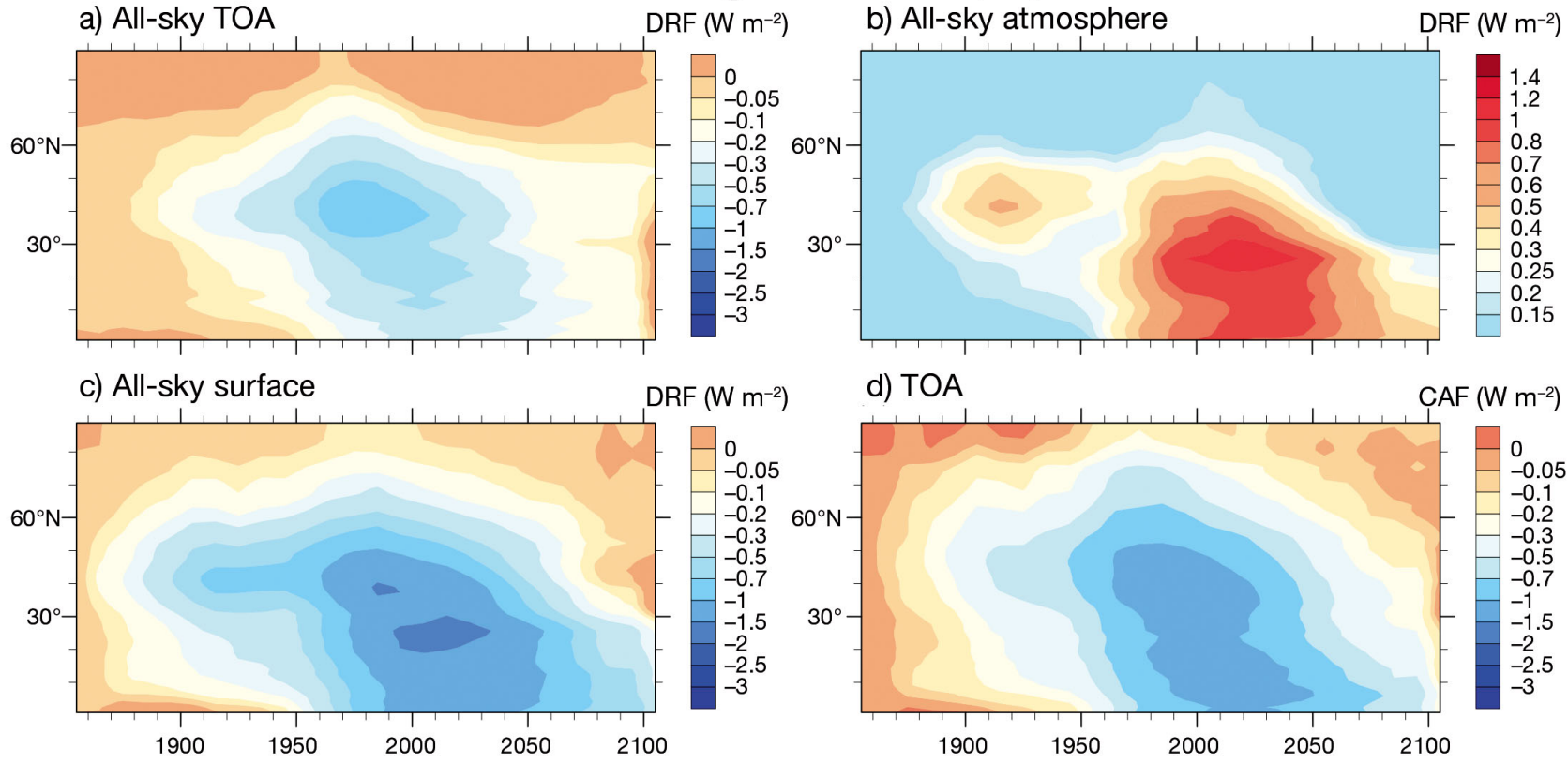

Historical change and RCP8.5 projection
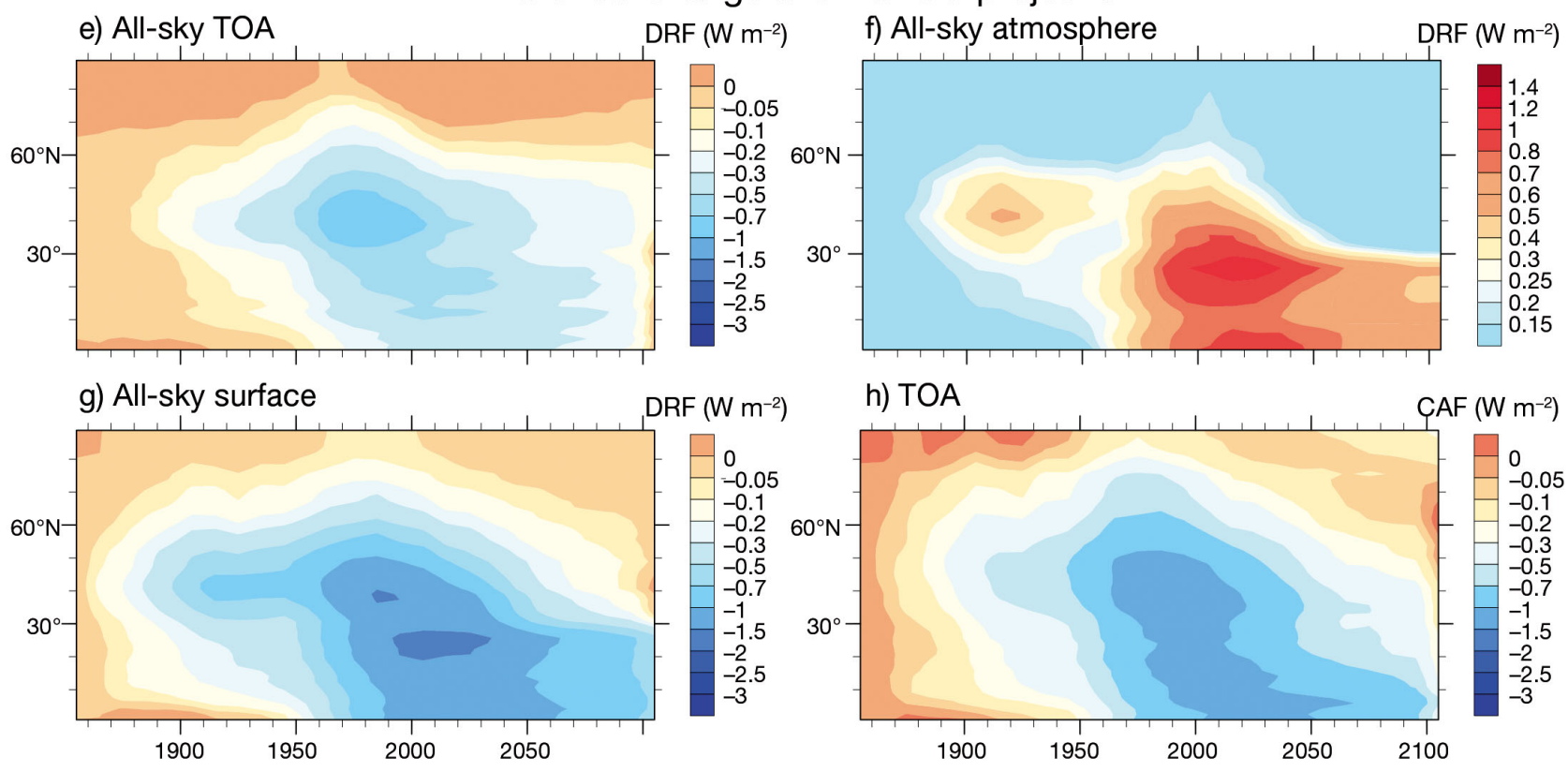

Fig. 6. Time evolution of zonal-averaged anthropogenic aerosol (a-c, e-g) direct radiative forcing (DRF) and (d-h) cloud albedo forcing (CAF). (a) At top of the atmosphere (TOA), (b) in the whole atmosphere, (c) at the surface, and (d) CAF under RCP4.5; $(\mathrm{e}-\mathrm{h})$ corresponding aerosol RFs under RCP8.5. Note: DRF is relative to pre-industrial (PI) values and for all-sky conditions

at most sites, which indicates that the aerosol simulation used in this study seriously underestimates the 2 aerosol surface mass concentrations. The largest aerosol mass is distributed in the low-level atmosphere, so the anthropogenic AOD and TOA DRF dominated by sulfate and the atmospheric DRF mainly by BC may also be underestimated over China. To roughly compare our calculated AOD with the observation, Fig. 11 presents the satellite retrieved AOD at $0.55 \mu \mathrm{m}$ for small mode aerosols, which are mainly contributed by anthropogenic activities. Although the spatial pattern of AOD is basically reproduced, its magnitude over East Asia is much weaker than the satellite dataset, especially in Eastern China, where most serious anthropogenic small mode aerosols exist (Van Donkelaar et al. 
Table 4. Peak periods and values of aerosol radiative forcing (RF) (DRF: direct RF and CAF: cloud albedo forcing) relative to pre-industrial values. Parentheses: results for clear-sky conditions. Different values in RCP4.5 and RCP8.5 are presented for projected DRF

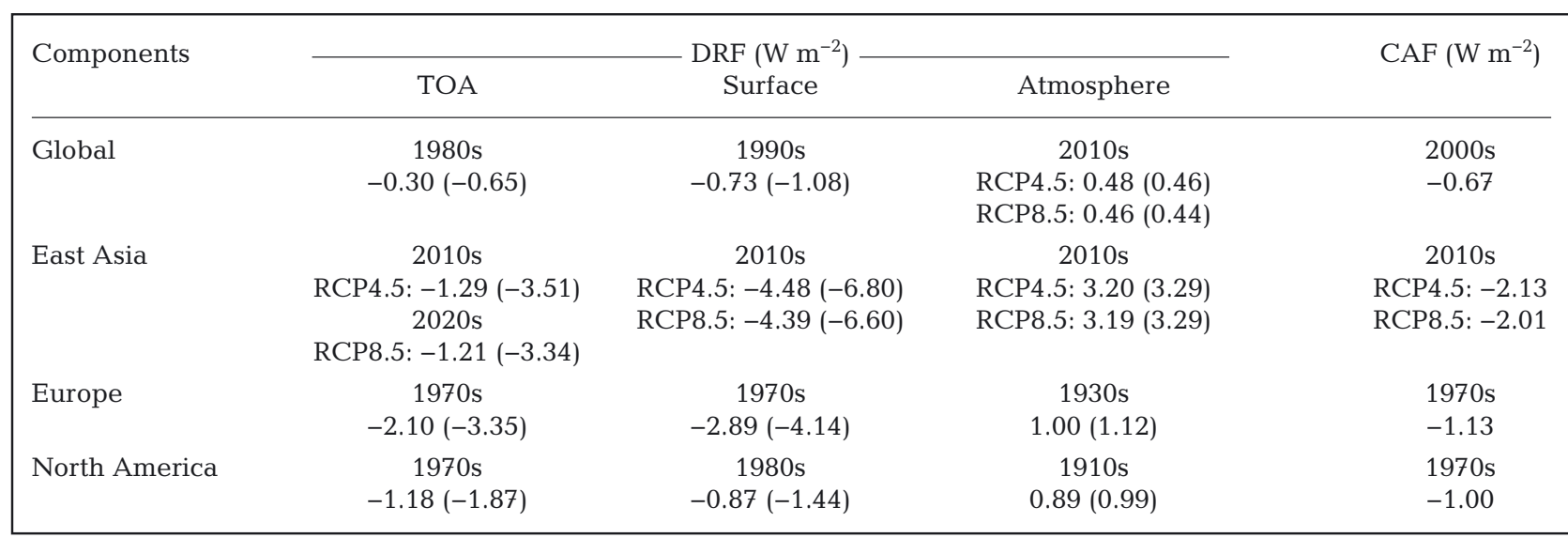
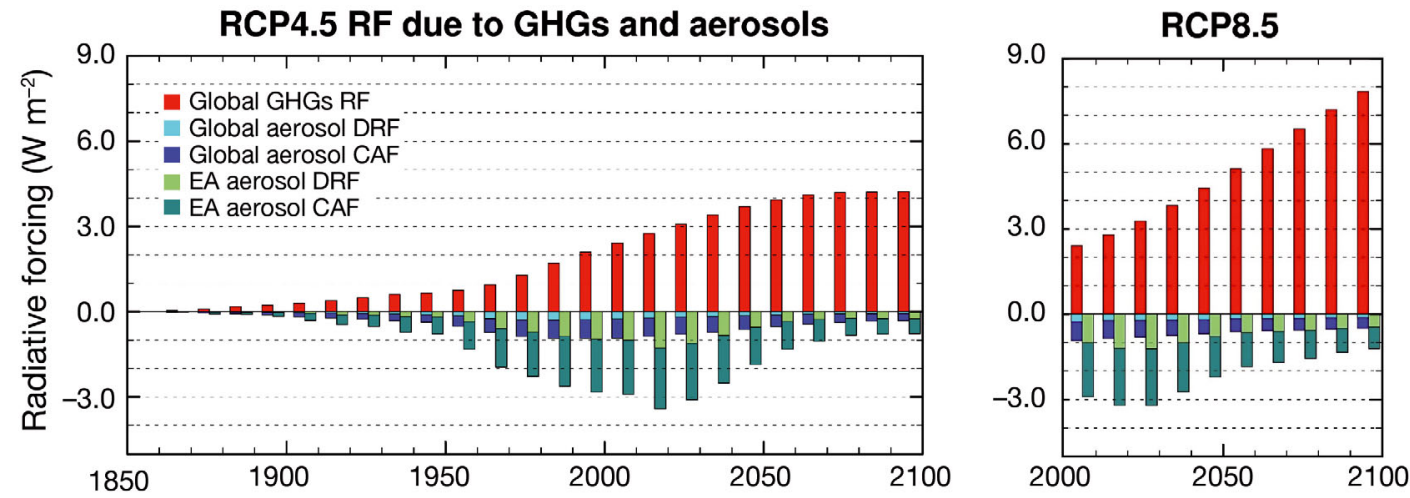

Fig. 7. Cumulative bar graph for the time series of RF due to greenhouse gases (GHGs) and aerosols relative to the pre-industrial era. Red bar: global mean GHG RF at TOA; light and deep blue bars: global mean aerosol DRF and CAF at the all-sky TOA, respectively; Light and deep green bars: corresponding results for the East Asian mean DRF and CAF, respectively. Total length of blue or green bar: combined value from aerosol DRF and CAF. Scenarios: RCP4.5 (left) and RCP8.5 (right)

2010). Thus, since major aerosol mass and resulting AOD are underestimated, the calculated clear-sky DRF is easily influenced in a similar way. Moreover, considering strong hygroscopic effects by hydrophilic sulfate, underestimation of sulfate mass definitely then reduces the magnitude of atmospheric column AOD and clear-sky DRF at the TOA and surface. In fact, the model work by Liu et al. (2012) and Shindell et al. (2013) also revealed that simulated AOD over Eastern China is weaker than observations. So, at least based on this study, present aerosol DRF over East Asia should very likely stay at a higher level than the estimations.

\section{CONCLUSION AND DISCUSSION}

This study uses long-term aerosol data simulated from the NCAR CAM-Chem model as inputs to the
LASG AGCM to study the decadal variation of anthropogenic aerosol DRF and CAF with the emphasis on East Asia. The major conclusions from the study can be summarized as follows.

In terms of the global mean, the largest DRF at the all-sky TOA $\left(-0.30 \mathrm{~W} \mathrm{~m}^{-2}\right)$ and CAF $\left(-0.67 \mathrm{~W} \mathrm{~m}^{-2}\right)$ relative to PI occur in the 1980 s and 2000 s, respectively, while a maximum atmospheric positive forcing of $0.48 \mathrm{~W} \mathrm{~m}^{-2}$, mainly due to $\mathrm{BC}$, is found around the 2010s for RCP4.5. The regional aerosol RF in the Northern Hemispheric industrial regions is much stronger than the global mean and shows a different temporal evolution. The aerosol RF (all-sky TOA DRF and CAF) peaks over Europe and North America around the early 1970s. In East Asia, the largest aerosol DRF occurs in the late 2010s for RCP4.5. Particularly, in developing Eastern China, the stronger negative surface and positive atmospheric DRF, due to absorbing aerosols, are projected to persist until 

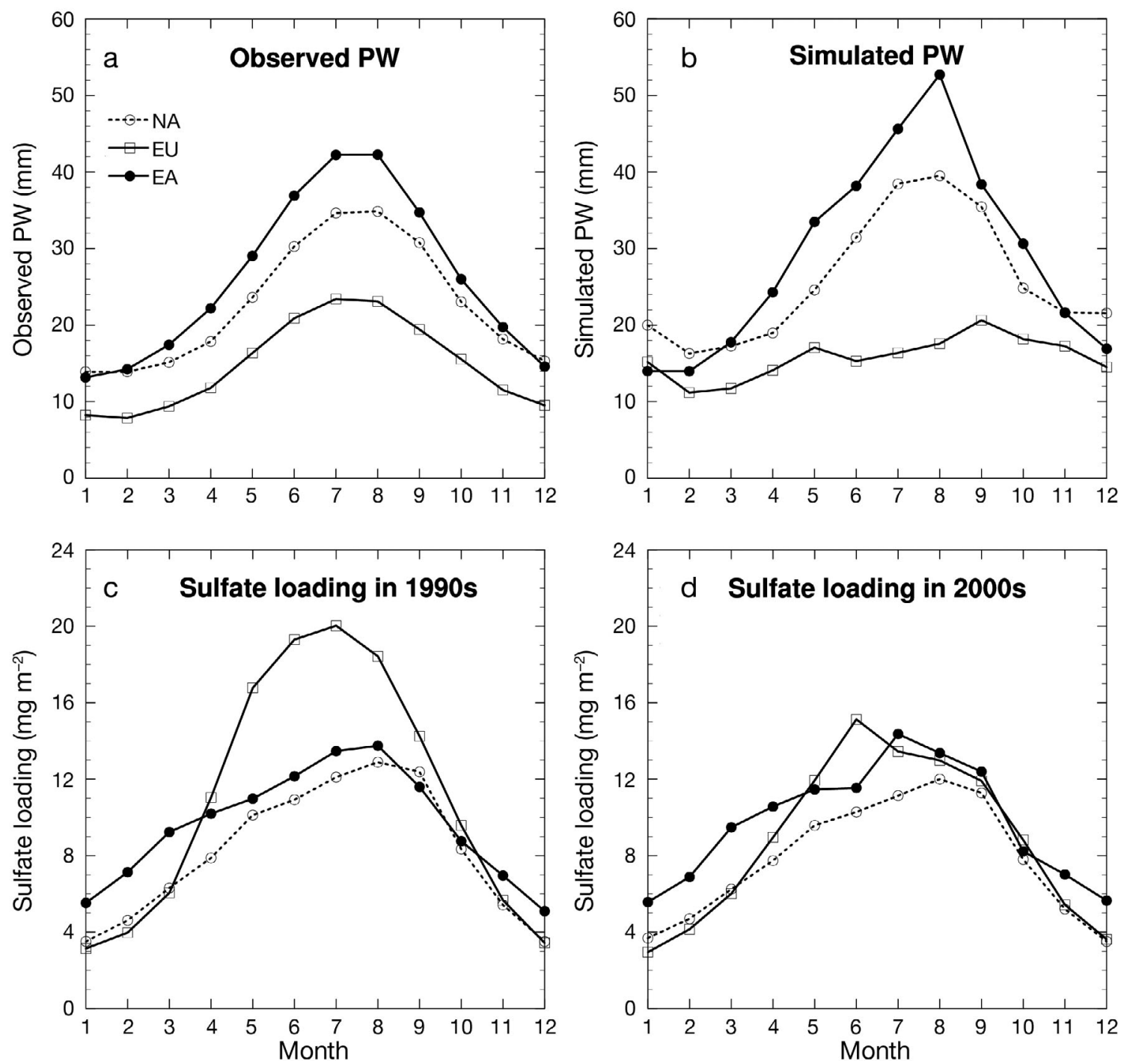

Fig. 8. Seasonal variation of (a) ERA-Interim observed and (b) simulated precipitable water (PW; mm); sulfate loading (mg m ${ }^{-2}$ ) in the (c) 1990s and (d) 2000s. NA: North America, EU: Europe, EA: East Asia

the 2030s, and the largest magnitude could be over $5.0 \mathrm{~W} \mathrm{~m}^{-2}$. Because of the rapidly decreasing DRF in Europe and North America, a greater contribution to projected aerosol DRF could be from East Asia, especially in the high-range RCP8.5 scenario. Therefore, a shift in aerosol RF centers from the mid-latitudes to low-latitudes started in the 1980s and is projected to become more obvious in the next decades. Meanwhile the combined negative aerosol direct RF and CAF (with a peak value of $-3.42 \mathrm{~W} \mathrm{~m}^{-2}$ in the $2020 \mathrm{~s}$ over East Asia under RCP4.5) could be comparable in magnitude to the positive RF attributed to GHGs. Furthermore, and perhaps more importantly, the higher atmospheric moisture over East Asia helps to enhance the hygroscopic effects of hydrophilic aerosols, then strengthens resulting aerosol AOD and
DRF at clear-sky TOA and surface, and even influence their long-term change. The simulation biases of air moisture in our AGCM also add some uncertainties for estimating regional aerosol DRF. The observational comparisons reveal that present simulated surface concentrations of key anthropogenic aerosol species (sulfate and BC) and resulting optical depths are highly underestimated in Eastern China. This underestimation very likely makes the anthropogenic aerosol DRF over Eastern China and even East Asia lower than the actual values. So, further studies should be conducted in order to improve East Asian aerosol regional features in climate models.

Clearly, the results in this study have many uncertainties. (1) The aerosol mass dataset provided by the NCAR CAM-Chem is subject to uncertainties in the 

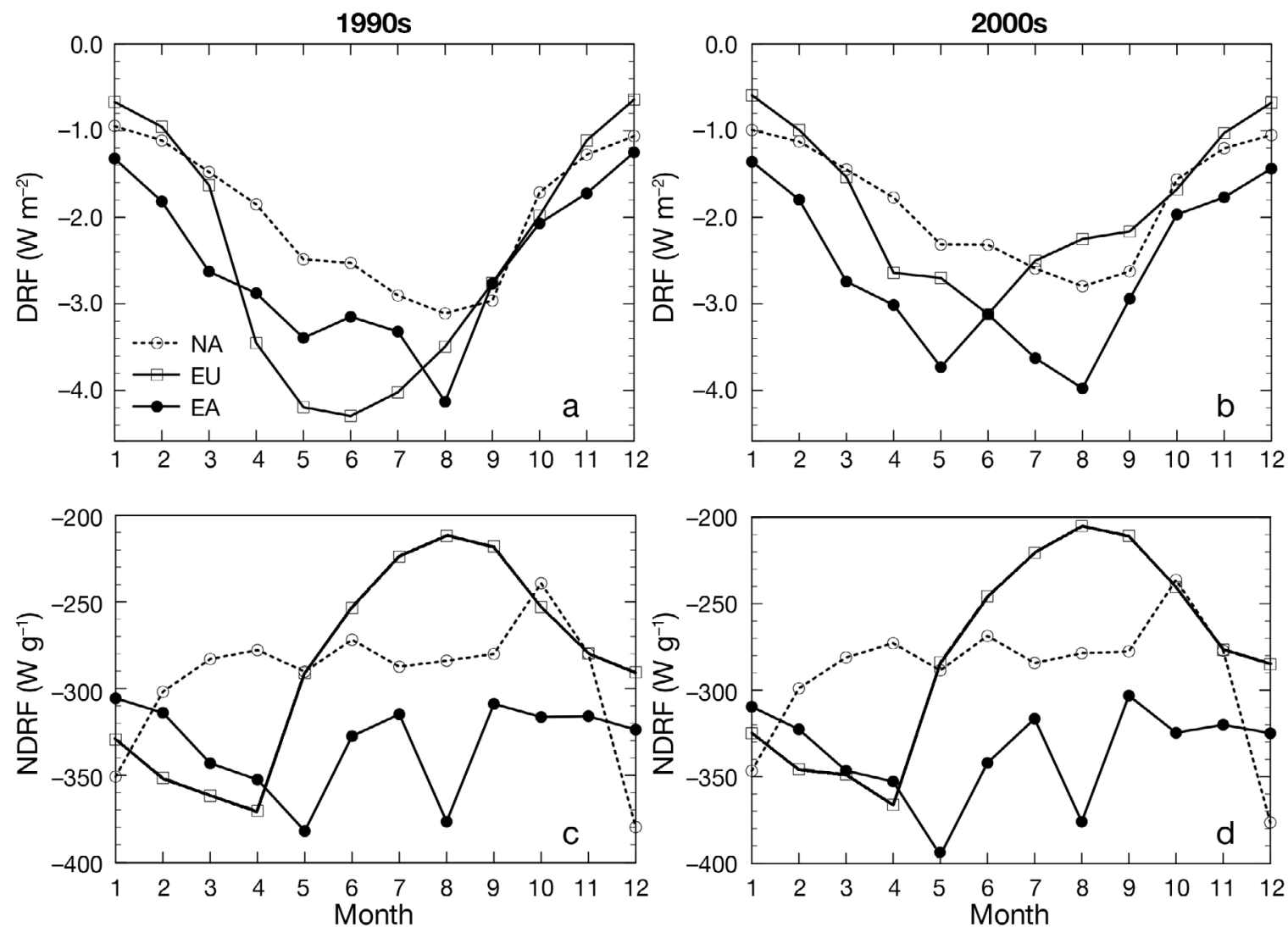

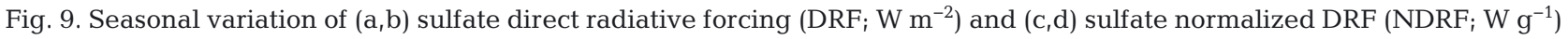
(normalized by its loading) at clear-sky top of the atmosphere in the $(a, c) 1990$ s and $(b, d) 2000$ s. See Fig. 8 for acronyms

surface emissions of aerosol precursors and resulting atmospheric loading, especially for East Asia. The multi-model comparison results by Myhre et al. (2013) showed that the largest uncertainties in aerosol DRF due to anthropogenic aerosol species lies in East Asia. Hence, further model and observational studies are needed to examine aerosol RF at
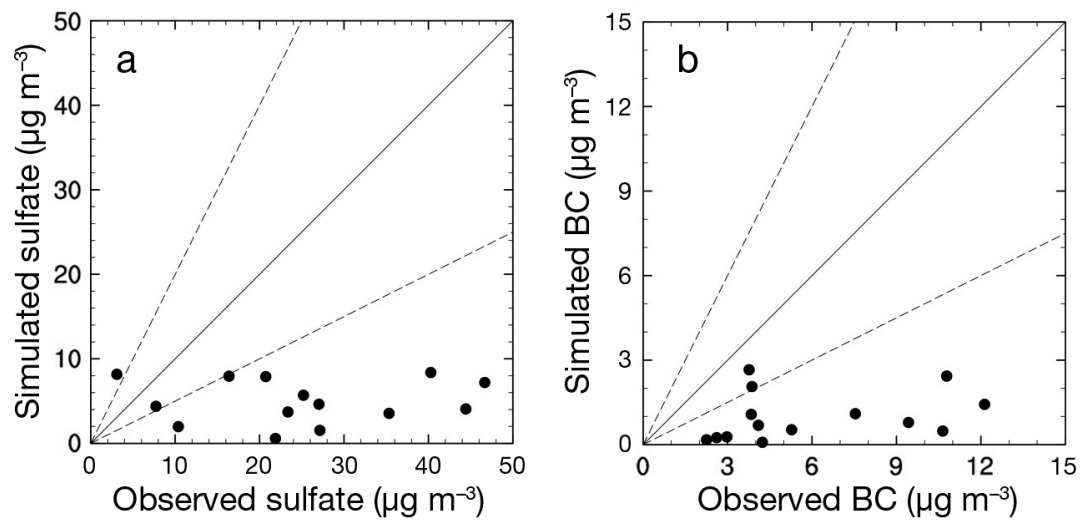

Fig. 10. Modeled (interpolated to observational sites) and observed annual mean surface (a) sulfate and (b) black carbon (BC) concentration in China. Simulation and observational periods are the 2000s and 2006-2007, respectively.

Solid line = 1:1 line; dashed lines $=1: 2$ and 2:1 lines regional scales to reduce relevant uncertainties. (2) The aerosol DRF depends highly on the aerosol radiative properties. In this study, BC is treated as a dry aerosol and the hygroscopic effect is ignored. This treatment tends to underestimate aerosol DRF. The external mixing treatment is used in our work because of aerosol dataset and model limitations, but internal mixing among different aerosol species generally exists in many real cases, which has direct effects on aerosol DRF (Ghan \& Zaveri 2007). Necessary attention to these issues should be paid in further studies. (3) This study does not consider the contribution of nitrate to CAF. Earlier work (Liao \& Seinfeld 2005, Bellouin et al. 2011) pointed out that nitrate emissions are increasing rapidly, and its contribution to aerosol RF could exceed sulfate in the late 21st century; therefore, it is important to include nitrate aerosols into aerosol CAF, especially when examining the projected change. (4) The aerosol RF 

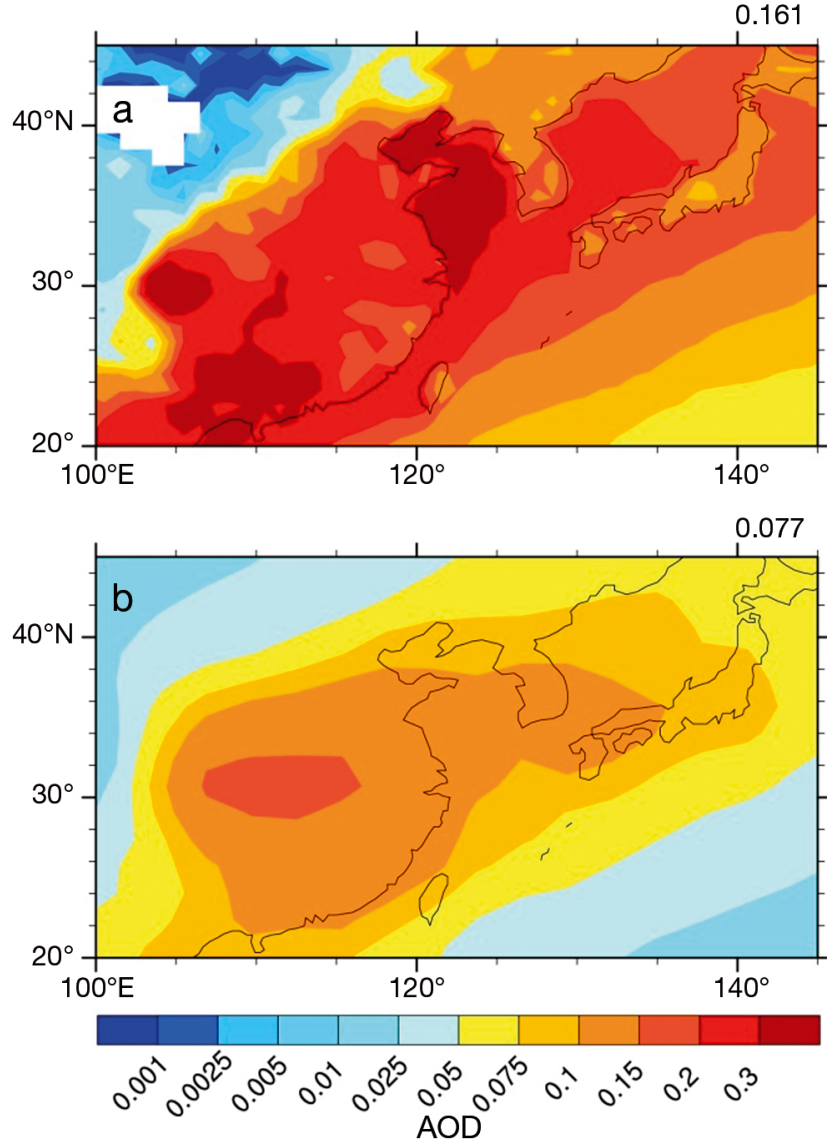

Fig. 11. Distribution of annual mean (a) MODIS fine-model aerosol optical depth (AOD) at $0.55 \mu \mathrm{m}$ and (b) calculated anthropogenic AOD at $0.50-0.625 \mu \mathrm{m}$ over East Asia. Here, MODIS data period is 2001-2010; simulation is 2000s relative to 1850 s. Values at top right: regional means

is certainly subject to biases inherent in the model simulations of atmospheric moisture and clouds. Substantial differences exist between simulated and these observed meteorological conditions. Some improvements in climate models (including our AGCM) processes are expected to reduce aerosol DRF uncertainties caused by model biases. Moreover, the aerosol CAF is closely related to not only aerosol mass, but also their number distribution. The empirical formula for relating aerosol to CDNC and the following cloud optical properties cannot represent CAF well in some cases. For example, there are many disadvantages if the empirical method based on present and regional observations is used in other periods or regions (Pringle et al. 2009). So increasingly, studies tend to use mechanistic methods to treat aerosolcloud relations (Ghan \& Schwartz 2007, Cheng et al. 2010). However, it should be pointed out that simulated aerosol states and model parameterization differ significantly in present climate models, which then bring some difficulties for estimating aerosol indirect $\mathrm{CAF}$, even if mechanistic methods are used. Considering such large uncertainties in estimating aerosol RF, it is necessary for the community to use multiple methods, including empirical, mechanistic, and observation-based approaches to examine aerosol RF and reduce the regional uncertainties.

Acknowledgements. This research was supported jointly by a grant from the National Basic Research Program of China (Nos. 2013CB955803 and 2012CB955303) and from a grant (to SUNYA) from the Office of Biological and Environmental Sciences, US Department of Energy. The authors thank Dr. Lamarque at NCAR for providing the NCAR CAM-Chem aerosol mass dataset and Dr. Qing Bao at LASG for helpful suggestions.

\section{LITERATURE CITED}

Abdul-Razzak H, Ghan SJ (2002) A parameterization of aerosol activation 3. Sectional representation. J Geophys Res 107(D3), doi:10.1029/2001JD000483

Adams PJ, Seinfeld JH, Koch D, Mickley L, Jacob D (2001) General circulation model assessment of direct radiative forcing by the sulfate-nitrate-ammonium-water inorganic aerosol system. J Geophys Res 106(D1):1097-1112

Albrecht BA (1989) Aerosols, cloud microphysics, and fractional cloudiness. Science 245:1227-1230

Bao Q, Wu GX, Liu YM, Yang J, Wang Z, Zhou T (2010) An introduction to the coupled model FGOALS1.1-s and its performance in East Asia. Adv Atmos Sci 27:1131-1142

Bellouin N, Rae J, Jones A, Johnson C, Haywood J, Boucher O (2011) Aerosol forcing in the Climate Model Intercomparison Project (CMIP5) simulations by HadGEM2 ES and the role of ammonium nitrate. J Geophys Res 116: D20206, doi:10.1029/2011JD016074

Bond TC, Bhardwaj E, Dong R, Jogani R and others (2007) Historical emissions of black and organic carbon aerosol from energy-related combustion 1850-2000. Global Biogeochem Cycles 21:GB2018, doi:10.1029/2006GB002840

Boucher O, Lohmann U (1995) The sulphate-CCN-cloud albedo effect: a sensitivity study with two general circulation models. Tellus 47B:281-300

Carslaw KS, Boucher O, Spracklen DV, Mann GW, Rae JL, Woodward S, Kulmala M (2010) A review of natural aerosol interactions and feedbacks within the Earth system. Atmos Chem Phys 10:1701-1737

Chang WY, Liao H (2009) Anthropogenic direct radiative forcing of tropospheric ozone and aerosols from 1850 to 2000 estimated with IPCC AR5 emissions inventories. Atmos Ocean Sci Lett 2:201-207

Cheng CT, Wang WC, Chen JP (2010) Simulation of the effects of increasing cloud condensation nuclei on mixed-phase clouds and precipitation of a front system. Atmos Res 96:461-476

Chou MD, Lee KT, Yang P (2002) Parameterization of shortwave cloud optical properties for a mixture of ice particle habits for use in atmospheric models. J Geophys Res 107: D21, 4600, doi:10.1029/2002JD002061

Edwards JM, Slingo A (1996) A studies with a flexible new radiation code. I. Choosing a configuration for a largescale model. QJR Meteorol Soc 122:689-720 
Ekman AML (2014) Do sophisticated parameterizations of aerosol-cloud interactions in CMIP5 models improve the representation of recent observed temperature trends? J Geophys Res 119:817-832, doi:10.1002/2013JD020511

Folini D, Wild M (2011) Aerosol emissions and dimming/ brightening in Europe: sensitivity studies with ECHAM5 HAM. J Geophys Res 116:D21104, doi:10.1029/2011JD 016227

Forster P, Ramaswamy V, Artaxo P, Berntsen T and others (2007) Changes in atmospheric constituents and in radiative forcing. In: Solomon S, Qin D, Manning M, Chen Z and others (eds) Climate change 2007: the physical science basis. Contribution of Working Group I to the Fourth Assessment Report of the Intergovernmental Panel on Climate Change. Cambridge University Press, Cambridge

$>\mathrm{Fu} \mathrm{Q}$, Liou KN (1992) On the correlated $k$-distribution method for radiative transfer in nonhomogeneous atmospheres. J Atmos Sci 49:2139-2156

> Ghan SJ, Schwartz SE (2007) Aerosol properties and processes: a path from field and laboratory measurements to global climate models. Bull Am Meteorol Soc 88: 1059-1083

Ghan SJ, Zaveri RA (2007) Parameterization of optical properties for hydrated internally mixed aerosol. J Geophys Res 112:D10201, doi:10.1029/2006JD007927

> Haywood JM, Ramaswamy V (1998) Global sensitivity studies of the direct radiative forcing due to anthropogenic sulphate and black carbon aerosols. J Geophys Res 103: 6043-6058

> He B, Bao Q, Li J, Wu G, Liu Y, Wang X, Sun Z (2013) Influences of external forcing changes on the summer cooling trend over East Asia. Clim Change 117:829-841

> Hess M, Koepke P, Schult I (1998) Optical properties of aerosols and clouds: the software package OPAC. Bull Am Meteorol Soc 79:831-844

> Hu YX, Stamnes K (1993) An accurate parameterization of the radiative properties of water clouds suitable for use in climate models. J Clim 6:728-742

Kiehl JT, Schneider TL, Rasch PJ, Barth MC, Wong J (2000) Radiative forcing due to sulfate aerosols from simulations with the National Center for Atmospheric Research Community Climate Model Version 3. J Geophys Res 105(D1):1441-1457

> Lamarque JF, Kyle GP, Meinshausen M, Riahi K and others (2011) Global and regional evolution of short-lived radiatively-active gases and aerosols in the Representative Concentration Pathways. Clim Change 109:191-212

> Lamarque JF, Emmons LK, Hess PG, Kinnison DE and others (2012) CAM-chem: description and evaluation of interactive atmospheric chemistry in the Community Earth System Model. Geosci Model Dev 5:369-411

$>$ Li J, Barker HW (2005) A radiation algorithm with correlated $k$-distribution. Part I: local thermal equilibrium. J Atmos Sci 62:286-309

Li D, Shine KP (1995) University of Reading, UGAMP Ozone Climatology. NCAS British Atmospheric Data Centre. http://badc.nerc.ac.uk/view/badc.nerc.ac.uk_ATOM_ dataent_UGAMPO3 (accessed in 2013)

> Li J, Wong JGD, Dobbie JS, Chylek P (2001) Parameterization of the optical properties and growth of sulfate aerosols. J Atmos Sci 58:193-209

Li Z, Li C, Chen H, Tsay SC and others (2011) East Asian studies of tropospheric aerosols and their impact on regional climate (EASTAIRC): an overview. J Geophys
Res 116:D00K34, doi:10.1029/2010JD015257

Li JD, Sun ZA, Liu YM, Li J, Wang WC, Wu G (2012) A study on sulfate optical properties and direct radiative forcing using the LASG-IAP general circulation model. Adv Atmos Sci 29:1185-1199

Liao H, Seinfeld JH (2005) Global impacts of gas-phase chemistry-aerosol interactions on direct radiative forcing by anthropogenic aerosols and ozone. J Geophys Res 110:D18208, doi:10.1029/2005jd005907

> Liao H, Adams PJ, Chung SH, Seinfeld JH, Mickley LJ, Jacob DJ (2003) Interactions between tropospheric chemistry and aerosols in a unified general circulation model. J Geophys Res 108:D14001, doi:10.1029/2001JD001260

> Martin GM, Johnson DW, Spice A (1994) The measurement and parameterization of effective radius of droplets in warm stratocumulus clouds. J Atmos Sci 51:1823-1842

> Menon S, Hansen J, Nazarenko L, Luo YF (2002) Climate effects of black carbon aerosols in China and India. Science 297:2250-2253

> Ming Y, Ramaswamy V, Ginoux PA, Horowitz LW, Russell LM (2005) Geophysical Fluid Dynamics Laboratory general circulation model investigation of the indirect radiative effects of anthropogenic sulfate aerosol. J Geophys Res 110:D22206, doi:10.1029/2005JD006161

> Moss RH, Edmonds JA, Hibbard KA, Manning MR and others (2010) The next generation of scenarios for climate change research and assessment. Nature 463:747-756

> Myhre G, Myhre A, Stordal F (2001) Historical evolution of radiative forcing of climate. Atmos Environ 35:2361-2373

> Myhre G, Samset BH, Schulz M, Balkanski Y and others (2013) Radiative forcing of the direct aerosol effect from AeroCom Phase II simulations. Atmos Chem Phys 13: 1853-1877

> Nenes A, Seinfeld JH (2003) Parameterization of cloud droplet formation in global climate models. J Geophys Res 108:D14, 4415, doi:10.1029/2002JD002911

> Ocko IB, Ramaswamy V, Ginoux P, Ming Y, Horowitz LW (2012) Sensitivity of scattering and absorbing aerosol direct radiative forcing to physical climate factors. J Geophys Res 117:D20203, doi:10.1029/2012JD018019

> Pringle KJ, Carslaw KS, Spracklen DV, Mann GM, Chipperfield MP (2009) The relationship between aerosol and cloud drop number concentrations in a global aerosol microphysics model. Atmos Chem Phys 9:4131-4144

Q Qian Y, Gong D, Fan J, Leung LR, Bennartz R, Chen D, Wang W (2009) Heavy pollution suppresses light rain in China: observations and modeling. J Geophys Res 114: D00K02, doi:10.1029/2008JD011575

Quaas J, Boucher O, Lohmann U (2006) Constraining the total aerosol indirect effect in the LMDZ and ECHAM4 GCMs using MODIS satellite data. Atmos Chem Phys 6: 947-955

Ramaswamy V, Boucher O, Haigh J, Hauglustaine $\mathrm{H}$ and others (2001) Radiative forcing of climate change. In: Houghton JT, Ding Y, Griggs DJ, Noguer M and others (eds) Climate change 2001: the scientific basis. Contribution of Working Group I to the Third Assessment Report of the Intergovernmental Panel on Climate Change. Cambridge University Press, Cambridge, p 349-416

Schulz M, Textor C, Kinne S, Balkanski Y and others (2006) Radiative forcing by aerosols as derived from the AeroCom present-day and pre-industrial simulations. Atmos Chem Phys 6:5225-5246

Shindell DT, Lamarque JF, Schulz M, Flanner M and others (2013) Radiative forcing in the ACCMIP historical and 
future climate simulations. Atmos Chem Phys 13: 2939-2974

Skeie RB, Berntsen TK, Myhre G, Tanaka K, Kvalevaag MM, Hoyle CR (2011) Anthropogenic radiative forcing time series from pre-industrial times until 2010. Atmos Chem Phys 11:11827-11857

Smith SJ, Aardenne JV, Klimont Z, Andres RJ, Volke A, Delgado Arias S (2011) Anthropogenic sulfur dioxide emissions: 1850-2005. Atmos Chem Phys 11:1101-1116

Sun Z (2008) Development of the Sun-Edwards-Slingo radi;ation scheme (SES2). Tech Rep No. 009, The Centre for Australian Weather and Climate Research (CAWCR) Melbourne

Sun Z (2011) Improving transmission calculations for the Edwards-Slingo radiation scheme using a correlated- $k$ distribution method. QJR Meteorol Soc 137:2138-2148

Sun Z, Rikus L (2004) Validating model clouds and their optical properties using geostationary satellite imagery. Mon Weather Rev 132:2006-2020

> Takemura T (2012) Distributions and climate effects of atmospheric aerosols from the preindustrial era to 2100 along Representative Concentration Pathways (RCPs) simulated using the global aerosol model SPRINTARS. Atmos Chem Phys 12:11555-11572

Takemura T, Tsushima Y, Yokohata T, Nozawa T, Nagashima T, Nakajima T (2006) Time evolutions of various radiative forcings for the past 150 years estimated by a general circulation model. Geophys Res Lett 33:L19705, doi:10.1029/2006GL026666

Taylor KE, Stouffer RJ, Meehl GA (2012) An overview of CMIP5 and the experiment design. Bull Am Meteorol Soc 93:485-498

Toon OB, Pollack JB, Khare BN (1976) The optical constants of several atmospheric aerosol species: ammonium sulfate, ammonium oxide and sodium chloride. J Geophys Res 81:5733-5748

Twomey SA (1977) The influence of pollution on the short-

Editorial responsibility: Oliver Frauenfeld,

College Station, Texas, USA wave albedo of clouds. J Atmos Sci 34:1149-1152

Uppala S, Dee D, Kobayashi S, Berrisford P, Simmons A (2008) Towards a climate data assimilation system: status update of ERA-Interim. European Centre for MediumRange Weather Forecasts (ECMWF). Newsl 115, p 12-18 Van Donkelaar A, Martin RV, Brauer M, Kahn R, Levy R, Verduzco C, Villeneuve PJ (2010) Global estimates of ambient fine particulate matter concentrations from satellite-based aerosol optical depth: development and application. Environ Health Perspect 118:847-855

Wang B (2006) The Asian monsoon. Springer/Praxis, New York, NY

Wang WC, Chen JP, Isaksen ISA, Tsai IC, Noone K, McGuffie K (2011) Climate-chemistry interaction: future tropospheric ozone and aerosols. In: Henderson-Sellers A, McGuffie K (eds) The future of the world's climate. Elsevier, Amsterdam, p 367-399

Wild M (2009) Global dimming and brightening: a review. J Geophys Res 114:D00D16, doi:10.1029/2008JD011470

Wu G, Liu Y, He B, Bao Q, Duan A, Jin FF (2012) Thermal controls on the Asian summer monsoon. Sci Rep 2:404, doi:10.1038/srep00404

Yu F, Ma X, Luo G (2013) Anthropogenic contribution to cloud condensation nuclei and the first aerosol indirect climate effect. Environ Res Lett 8:024029

Zhang XY, Wang YQ, Niu T, Zhang XC, Gong SL, Zhang YM, Sun JY (2012) Atmospheric aerosol compositions in China: spatial/temporal variability, chemical signature, regional haze distribution and comparisons with global aerosols. Atmos Chem Phys 12:779-799

Zhao XJ, Zhao PS, Xu J, Meng W and others (2013) Analysis of a winter regional haze event and its formation mechanism in the North China Plain. Atmos Chem Phys 13: 5685-5696

Zhou C, Penner JE, Ming Y, Huang XL (2012) Aerosol forcing based on CAM5 and AM3 meteorological fields. Atmos Chem Phys 12:9629-9652

Submitted: May 13, 2013; Accepted: April 27, 2014

Proofs received from author(s): September 29, 2014 